\title{
Dependency of cohesive laws of a structural adhesive in Mode-I and Mode-II loading on moisture, freeze-thaw cycling, and their synergy
}

\author{
Mohsen Heshmati *, Reza Haghani, Mohammad Al-Emrani \\ Dept. of Civil and Environmental Engineering, Division of Structural Engineering, Chalmers University of Technology, Gothenburg, Sweden
}

\section{H I G H L I G H T S}

- The open-face geometry leads to accurate estimation of cohesive-laws if a strong and thin secondary adhesive bond is used.

- Saltwater reduced the peak stress of Mode-I cohesive-law which caused the largest reduction of fracture energy by $29 \%$.

- Combined freeze-thaw and saltwater led to the largest reduction of Mode-II fracture energy by $26 \%$.

- Exposure to environmental conditions were found to have different effects on Mode-I and Mode-II cohesive laws.

\section{A R T I C L E I N F O}

\section{Article history:}

Received 23 December 2016

Received in revised form 28 February 2017

Accepted 5 March 2017

Available online 6 March 2017

\section{Keywords:}

Durability

Adhesive joints

Fracture mechanics

Cohesive laws

Moisture

Freeze-thaw

\section{G R A P H I C A L A B S T R A C T}

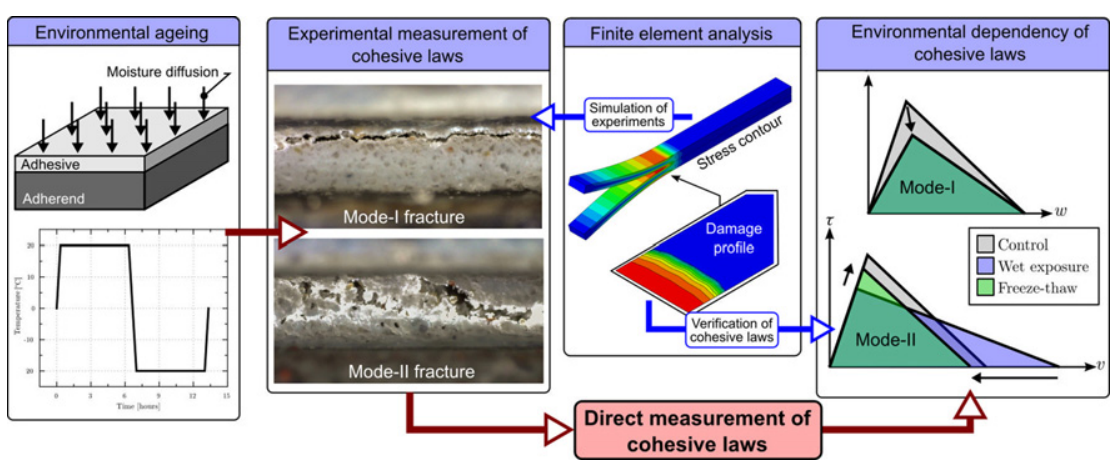

\begin{abstract}
A B S T R A C T
In recent years, adhesive bonding has found its way to construction applications such as bridges. Given the harsh conditions that such structures are usually exposed to, it is necessary to account for environmental factors, particularly moisture and temperature, in the design phase. Cohesive zone modelling has attracted much attention in the last decade as a promising method to design adhesive joints. Despite this interest, the effects of moisture and thermal cycles on cohesive laws have not been investigated to the knowledge of the authors. In this paper, we present a method to directly measure the environmental-dependent cohesive laws of a structural adhesive loaded in pure Mode-I and Mode-II. Special consideration is given to overcome issues such as the timeconsuming nature of moisture ingression and specimen dimensions, which could be problematic due to the size-limitations of conditioning equipment. The accuracy of this method was verified through simulation of the experiments using the finite element analysis. The effects of exposure to $95 \%$ relative humidity, immersion in saltwater and distilled water, and freeze-thaw cycles in the presence or absence of moisture were investigated. The results indicate the damaging effects of combined saltwater and freeze-thaw cycles which were clearly reflected on the shape of the cohesive laws.
\end{abstract}

(C) 2017 Elsevier Ltd. All rights reserved.

\section{Introduction}

Adhesive bonding is becoming an attractive alternative to traditional mechanical joining techniques used in the construction sector, such as

\footnotetext{
* Corresponding author at: Sven Hultins gata 8, SE-412 96 Gothenburg, Sweden.

E-mail address: mohsen.heshmati@chalmers.se (M. Heshmati).
}

welding and bolting. With the advances in polymer science, the development of toughened epoxy formulations has allowed adhesives to be used in more demanding conditions where load-bearing joints are required [1-4]. Bridges, which are potentially subjected to such conditions, can greatly benefit from the advantages of adhesive bonding such as easier in-situ assembly, rapid installation, cost efficiency, more uniform stress distribution, and elimination of local stress 
concentrations. An example application of adhesive joints in bridges is the use of bonded composite materials for strengthening and refurbishment purposes. Even though, the short-term behaviour of such joints has been extensively studied, the subject of durability and long-term performance has not been researched as much.

Many civil structures, such as bridges, are exposed to harsh environmental conditions during their service life. With a design life of up to 120 years it is essential that these structures are designed with focus on durability and long-term performance so as to minimize future inspection and maintenance costs. Hygrothermal ageing, which is a combination of moisture and thermal cycles, is the most common type of environmental exposure for such structures [5]. Therefore, it is crucial to consider the effect of hygrothermal exposure during the design phase of adhesive joints.

In the design of adhesive joints for structural engineering applications, a commonly used approach is to relate material strength data to load effects (i.e. stresses or strains) obtained from classical theory of elasticity. Such approach possesses several limitations. In general, elastic analysis resolves infinite stresses in locations of singularities such as at sharp corners and material interfaces, which are locations where failure of adhesive joints takes place. In addition, and particularly when hygrothermal effects need to be accounted for in design, stress/-strain approaches are not suitable to account for the non-uniform moisture/environmental-damage distribution profile in the adhesive layer of bonded joints. Therefore alternative design approaches are needed for these situations.

A solution to overcome the aforementioned limitations is to use the energy-based methods. In this context, linear elastic fracture mechanics (LEFM) may be useful, see, for example, [6]. Here, the fracture process in an adhesive joint is modelled by evaluating the stress intensity factor, $K$, at the tip of an initial flaw, i.e. crack tip. This is performed by first running a stress analysis, which, given the existence of a sharp crack, is clearly affected by stress singularity problems. The crack may grow if $K \geq K_{c}$, where $K_{c}$ is the critical fracture toughness of the material. The actual fracture process taking place in the adhesive layer is disregarded when using LEFM in which the singular domain at crack tip (also known as K-dominant zone) is assumed to be much smaller than other relevant dimensions, e.g. the adhesive layer thickness or height of adherends [7-9]. For an adhesive layer loaded in peel, Wang et al. [7] found this region to be equal to a small fraction of the adhesive layer thickness. For modern adhesives, nevertheless, the length of the fracture process zone ahead of a crack is generally much larger than the adhesive layer thickness and often even larger than the height of adherends, particularly when loaded in shear (see, for example [10, 11]). Therefore, the usefulness of LEFM methods for the design of adhesive joints is limited to very brittle adhesives containing cracks or other crack-like defects.

Cohesive zone modelling (CZM), which was first introduced by Barrenblatt [12] for metals, offers a computationally attractive solution to circumvent these problems. In this method, the stress singularity at the tip of a sharp crack is replaced with a process zone. Hence, the fracture formation is considered as a gradual process in which the separation of the crack surfaces takes place across an extended crack tip, or cohesive zone, and is resisted by cohesive tractions, see Fig. 1(a). The traction decreases with increasing separation of the two surfaces until it reaches zero, which indicates the formation of new crack surfaces. This process is simulated in the cohesive zone models by using "Cohesive laws", as depicted in Fig. 1(b).

In order for the CZM to provide accurate prediction of the mechanical behaviour of bonded joints, cohesive laws have to be characterized using appropriate experimental methods. Double cantilever beam (DCB) and end-notched flexure (ENF) specimens are the two most common configurations to obtain cohesive laws for adhesives. When properly designed, these configurations can give pure Mode I or Mode II state of stress at crack tip in adhesive layers, respectively, and provide stable crack growth which is necessary to obtain the softening part of

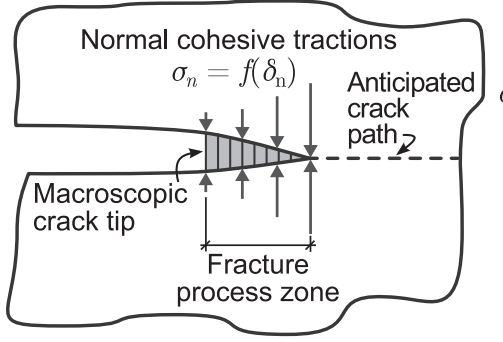

(a)

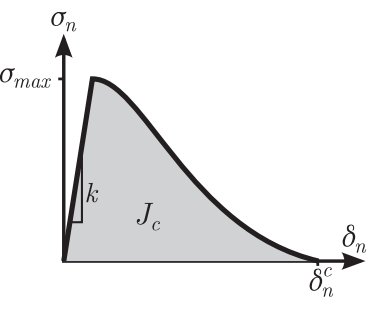

(b)
Fig. 1. (a) Illustration of a cohesive zone in an arbitrary cracked body, (b) a cohesive law providing the relationship between the normal tractions $\left(\sigma_{n}\right)$ and corresponding separations $\left(\delta_{n}\right)$ across the fracture process zone.

cohesive law [11,13]. Using such configurations, the cohesive laws can be determined employing a number of different techniques including the: (i) inverse method, (ii) property identification technique, and (iii) direct method. The inverse method is based on iterative FEsimulations with varying cohesive law to obtain the best fit to experimental measurements (see, e.g., [14]). The property identification technique is based on separate measurement of each parameter of cohesive law using suitable tests (see, e.g., [15]). While both of these methods rely on a basic assumption of the shape of cohesive law, the direct method is capable of providing the exact shape of cohesive law for the adhesive from experiments. This is achieved by differentiating the measured strain energy release rate with respect to the separation at crack tip. Several previous studies have demonstrated the applicability of the direct method to obtain the Mode I and Mode II cohesive laws of a number of adhesives in [9,11,16-20]. The direct method is used in this paper as it is the only approach that is capable of directly obtaining the cohesive laws from experiments. The cohesive laws obtained using this method include the effects of damage formation and non-linear deformation of the adhesive.

Environmental effects, particularly moisture and thermal cycles, can severely affect the mechanical properties of adhesives [21-25]. Moisture, which can take the form of humidity, liquid water or de-icing salt solutions, mainly affects adhesives through plasticisation, swelling, cracking and hydrolysis [26-29]. Cyclic freeze-thaw exposure is also a concern in many countries where it represents a typical outdoor condition [30]. Freeze-thaw cycles are usually associated with embrittlement, hardening and micro-cracking of adhesives [31,32] which can lead to loss of initial stiffness or strength [30,33,34]. In addition, at joint-level, a difference of coefficients of thermal expansion of adhesives and adherends can lead to degradation of adhesion properties through the formation of micro-cracks at interfaces [35-39]. Nevertheless, very little is known about the synergetic effects of moisture and freeze-thaw cycles. Considering the frequent exposure of many structures, such as bridges, to these environments and their crucial effect on the performance of bonded joints, there is an essential need for characterization of environmental dependent properties of adhesive bonds, particularly the cohesive laws.

To the knowledge of the authors, the effects of moisture or thermal cycles on Mode I or Mode II cohesive laws have not been investigated before. The influence of moisture on critical fracture energy has, however, been subject for some previous studies [40-43]. Wylde and Spelt [40] introduced the open-face specimen geometry to overcome some of the limitations of conventional closed specimens such as long moisture diffusion path and non-uniform state of damage across the bond surface, see Fig. 2. The open-face specimen, which consists of a layer of adhesive (primary) casted on only one adherend, significantly accelerates the diffusion by shortening the diffusion path and hence reducing the time for saturation. After environmental exposure, a stronger adhesive (secondary) is used to bond the second adherend and complete the test specimen. Nevertheless, Wylde and Spelt [40] concluded that the circumstance under which this configuration may affect the 


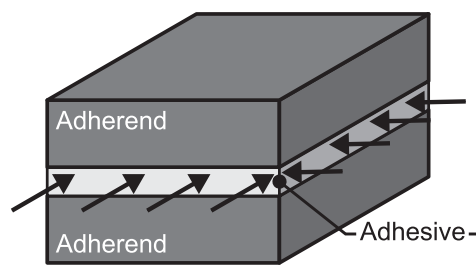

(a)

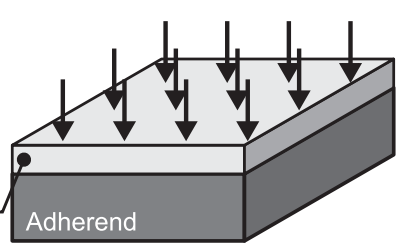

(b)
Fig. 2. (a) Conventional closed specimen, (b) open-face specimen. Arrows indicate primary moisture diffusion directions.

corresponding fracture energy needs further research. Loh et al. [41] and Ameli et al. [43] used open-face specimens in conjunction with LEFM to obtain moisture-dependent fracture properties of different adhesives. Although, they reported a reduction of mixed-mode fracture energy with increasing moisture content, the moisturedependent cohesive laws could not be determined as the LEFM approach was used. Liljedahl et al. [42] used open-face specimens along with the inverse method to obtain moisture-dependent parameters of mixed-mode cohesive laws. Due to the previously discussed limitations of this method, a bi-linear shape for cohesive law had to be assumed. No study of this kind has attempted to characterize the effects of freeze/taw cycling.

This paper aims to obtain the cohesive laws of a structural adhesive in Mode I and Mode II loading as a function of moisture content, freeze-thaw cycling, and their combined effect using an experimental approach. The cohesive laws are derived directly based on the Rice's [44] path-independent J-integral concept using DCB and ENF specimens. Finite element analyses using CZM are conducted to verify the accuracy of the experimental measurements and to determine the possible effects of the secondary adhesive layer of open-face specimens. The paper is concluded with a list of key-findings and suggestions for future work. This research paves the way towards a more accurate design of bonded joints with respect to durability and longterm performance.

\section{Experimental programme}

\subsection{Materials and specimens}

Three materials were used to manufacture the DCB and ENF specimens in this study: steel S355, primary adhesive STO® Lim 567, and secondary adhesive Loctite $₫$ EA 9466 . The complete stress-strain response of the steel material was obtained by testing three tensile coupons according to [45]. The results revealed an average Young's modulus of $200 \mathrm{GPa}$, yield stress of $330 \mathrm{MPa}$, and Poisson's ratio of 0.3. The properties of the used epoxy adhesives in dry condition are listed in Table 1 , while more details on fabrication and testing can be found in [46]. Moreover, the dependency of tensile properties of the primary adhesive (STO® Lim 567) on moisture was characterized by the authors in a recent study [47], and are reported in Table 2.

To manufacture the specimens, the steel plates were first sand blasted to a degree equivalent to SA2 $1 / 2$, as suggested in [48]. Then they

Table 1

Reference properties of the used epoxy adhesive materials.

\begin{tabular}{lll}
\hline Property & STO $®$ Lim 567 & Loctite ${ }^{\circ}$ EA 9466 \\
\hline Glass transition temperature, $T_{g}\left[{ }^{\circ} \mathrm{C}\right]$ & 55 & $62^{\mathrm{a}}$ \\
Cure time at $22{ }^{\circ} \mathrm{C}$, [days] & $7^{\mathrm{a}}$ & $1^{\mathrm{a}}$ \\
Young's modulus, $E[\mathrm{GPa}]$ & 7.1 & 2.4 \\
Poisson's ratio, $\nu$ & 0.3 & 0.3 \\
Tensile strength, $\sigma_{\max }[\mathrm{MPa}]$ & 34 & 34 \\
Tensile failure strain, $\varepsilon_{\max }[\%]$ & 1.0 & $<3.5$ \\
\hline
\end{tabular}

a Data provided by the manufacturer.
Table 2

Moisture-dependent properties of STO ${ }^{\circledR}$ Lim 567 epoxy adhesive aged in various environments [47].

\begin{tabular}{lllll}
\hline Environment & $\begin{array}{l}\text { Moisture } \\
\text { content } \\
{[\%]}\end{array}$ & $\begin{array}{l}\text { Young's } \\
\text { modulus } \\
{[\mathrm{GPa}]}\end{array}$ & $\begin{array}{l}\text { Tensile } \\
\text { strength } \\
{[\mathrm{MPa}]}\end{array}$ & $\begin{array}{l}\text { Tensile } \\
\text { failure } \\
\text { strain [\%] }\end{array}$ \\
\hline 45DW: distilled water at $45{ }^{\circ} \mathrm{C}$ & 1.48 & 3.72 & 23.8 & 1.35 \\
45SW: $5 \% \mathrm{NaCl}$ salt-water at $45{ }^{\circ} \mathrm{C}$ & 1.34 & 4.83 & 27.5 & 1.10 \\
45RH: $95 \%$ relative humidity at $45{ }^{\circ} \mathrm{C}$ & 1.10 & 4.43 & 26.3 & 0.93 \\
\hline
\end{tabular}

were cleaned with high-pressure air, followed by solvent (acetone) cleaning to remove steel particles, remaining from sand blasting, and other contaminations. This was directly followed by casting the primary adhesive layer on the steel adherend. The thickness and length of the adhesive layer were controlled by using PTFE sheets. Since the aim of these experiments is to measure the cohesive laws of an adhesive layer, no sharp crack is created. It should be noted that a crack, in a macroscopic sense, is defined as the part of the specimen where the adherends are not joined by the adhesive. Using this definition, the end of this crack, i.e. where adhesive starts, will be referred to as the "crack tip". Finally, a backing plate coated with plastic film was used to apply uniform pressure to remove the excessive adhesive. The backing plate was removed after three days. The specimens used in this study were manufactured in two consecutive days. The manufactured open-face specimens were cured for one month at room temperature prior to environmental exposure. Also, to ensure full-curing of the adhesive and to remove any initial moisture content, the specimens were cured for three days in an oven at $45^{\circ} \mathrm{C}$ as suggested in [49]. All the specimens were marked and categorized into two series according to their date of manufacture. For each ageing scenario, specimens were randomly selected with the condition that specimens from both series are included.

The open-face specimens were completed by bonding the second steel adherend using the secondary adhesive material. This was achieved by, first, gently roughening the surface of the primary bond with a 220 grit sandpaper to ensure a strong mechanical interlock. Then, an ultra-thin layer of the secondary adhesive was applied on the

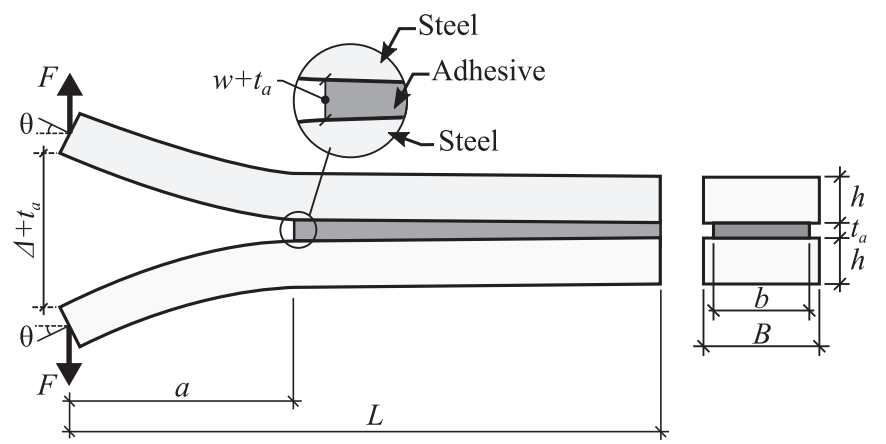

(a)

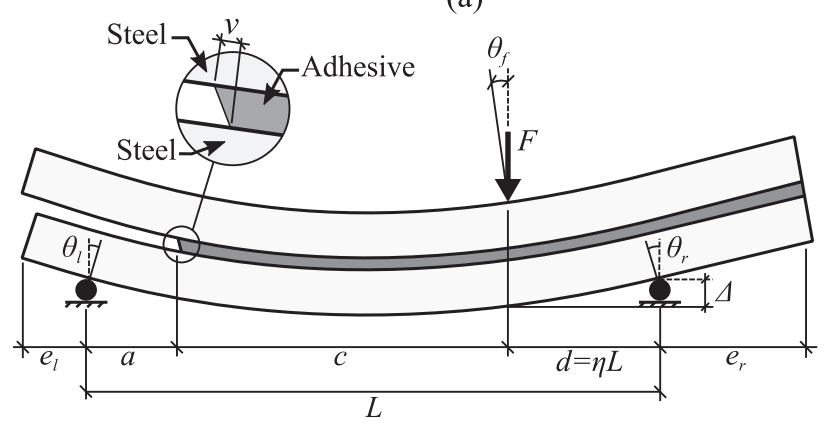

(b)

Fig. 3. Drawings of the manufactured specimens (deformed): (a) DCB, (b) ENF. 
Table 3

Dimensions of the manufactured test specimens according to Fig. 3; all dimensions are in $[\mathrm{mm}]$.

\begin{tabular}{llllllllll}
\hline Specimen & $\mathrm{L}$ & $\mathrm{a}$ & $\mathrm{d}$ & $\mathrm{e}_{\mathrm{l}}$ & $\mathrm{e}_{\mathrm{r}}$ & $\mathrm{t}_{\mathrm{a}}$ & $\mathrm{h}$ & $\mathrm{b}$ & $\mathrm{B}$ \\
\hline DCB & 330 & 115 & - & - & - & $1.15-1.25$ & 9.9 & 20 & 25 \\
ENF & 350 & 125 & 100 & 35 & 65 & $1.15-1.25$ & 9.9 & 20 & 25 \\
\hline
\end{tabular}

top surface of the primary adhesive and the second steel adherend. While the original PTFE sheets were used as spacers, the adherends were joined with a uniformly applied pressure on a table with alignment pins. The same PTFE spacers were used to cast a very thin layer of secondary adhesive while preventing the second steel adherend from undesirable bending beyond the crack tip as a result of the applied pressure. The specimen was then kept for one day at room temperature to cure the secondary adhesive, and was directly tested afterwards to minimize the effects of moisture desorption. This assumption was investigated using moisture diffusion finite element analysis according to the instructions given in [49]. The analysis results confirmed the negligible moisture loss in the adhesive layer following the used testing procedure. Fig. 4 shows a microscopic picture of the adhesive layer of a complete specimen. In general, this procedure led to specimens with a bond-line thicknesses of approx. 1.15-1.25 mm and 0.03-0.05 mm for the primary and secondary layers, respectively. Fig. 3 shows schematic drawings of the completed specimens with their dimensions listed in Table 3 . The peeling, $w$, and shear, $v$, deformations at the crack tip region are also manifested in this figure.

\subsection{Derivation of cohesive laws from measurements}

\subsubsection{Background}

The path-independent J-integral defined by Rice [44] is used to obtain the energy release rate, $J$ :

$J=\int_{C}\left(\sigma d \varepsilon d y-\boldsymbol{T} \cdot \frac{d \boldsymbol{u}}{d x} d C\right)$

where $C$ is any arbitrary counter-clockwise integration path, $\sigma$ and $\varepsilon$ denote the stress and strain tensors, and $\boldsymbol{T}$ and $\boldsymbol{u}$ the traction and displacement vectors, respectively. The $x$-axis is along the bond-line and $\mathrm{y}$ is perpendicular to $x$. It should be mentioned that Eq. (1) is valid for any

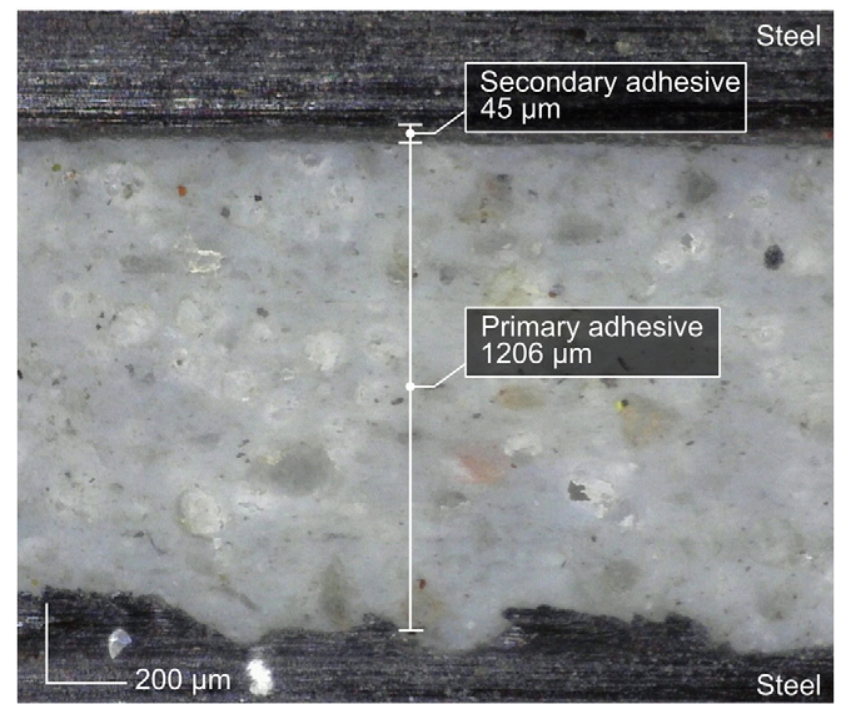

Fig. 4. Microscopic photograph showing the thicknesses of primary/secondary adhesive layers. non-linear elastic adherends provided that the adhesive layer has uniform thickness, width and mechanical properties along the $x$-axis. Using Eq. (1), it is shown by Högberg et al. [50] that the work of cohesive stresses within the cohesive zone (Jadhesive) can be expressed by:

$J_{\text {adhesive }}=\int_{0}^{w} \sigma(w, v) d w+\int_{0}^{v} \tau(w, v) d v$

where $w$ and $v$ are normal and shear deformations of the adhesive layer at crack tip, see Fig. 3. Furthermore, Sørensen and Kirkegaard [51] showed that the cohesive laws of the adhesive layer can be obtained by differentiating Eq. (2) as follows:

$\sigma(w, v)=\frac{\partial J_{\text {adhesive }}}{\partial w}, \quad \tau(w, v)=\frac{\partial J_{\text {adhesive }}}{\partial v}$

Therefore, provided a continuous measurement of Jadhesive and peeling or shear deformations at the adhesive front, the cohesive laws could be determined experimentally. The details of such measurements are elaborated in the next section.

\subsubsection{Measurement methods}

2.2.2.1. Mode I fracture energy. As mentioned before, DCB specimens are used to determine the mode I cohesive law. The estimation of fracture energy from DCB specimens can be done through the use of a number of different methods that are mainly derived based on LEFM [52]. Although the LEFM-based methods form the basis of the current standards (such as, ASTM D3433 [53]), it is demonstrated by Biel and Stigh [52] that their application to toughened adhesives with long fracture process zones can be accompanied with substantial error. The authors reported that the evaluated method based on the J-integral, however, yielded the most accurate outcome. Therefore, for a transversally loaded DCB specimen as shown in Fig. 3(a), Olsson and Stigh [54] derived an expression for calculation of $J$. This expression was later extended by Nilsson [55] to account for large deformations, and reads:

$J_{I}=\frac{2 F}{b} \sin (\theta)$

It should be noted that this equation was derived under the assumption of equal width of the adherends and adhesive layer. However, in the current study, the width of adherends was chosen slightly larger than that of the adhesive layer, cf. Table 3, for manufacturing reasons. When using Eq. (1), the strain energy release rate is evaluated for the material which undergoes damage. Therefore, for the used specimen in this study, the width of the adhesive layer (b) should be used in Eq. (4) and similar relations in the sequel as long as the rotations of the adherends are measured. Nevertheless, extensive care should be given since large differences between the adhesive and adherends width can lead to severe out-of-plane bending of the adherends which would affect the stress distribution in the adhesive layer. Careful evaluation of the specimens used in this study revealed insignificant error caused by this phenomenon.

Given a quasi-static loading scenario and continuous measurement of the applied force $(F)$ and the rotation of the steel adherends $(\theta)$, the development of $J$ from zero to $J_{c}$ (critical fracture energy) could be continuously obtained using Eq. (4). Consequently, the measurement setup depicted in Fig. 5 was developed using a test rig and an MTS universal testing machine. As can be seen, the loading fixture is designed to allow the arms of the DCB specimen to rotate freely. In addition, the magnitude of rotation of each arm is continuously calculated using two fixed LVDTs with a horizontal distance of $100 \mathrm{~mm}$ measuring the vertical displacement of two points on a glued extension bar. The 


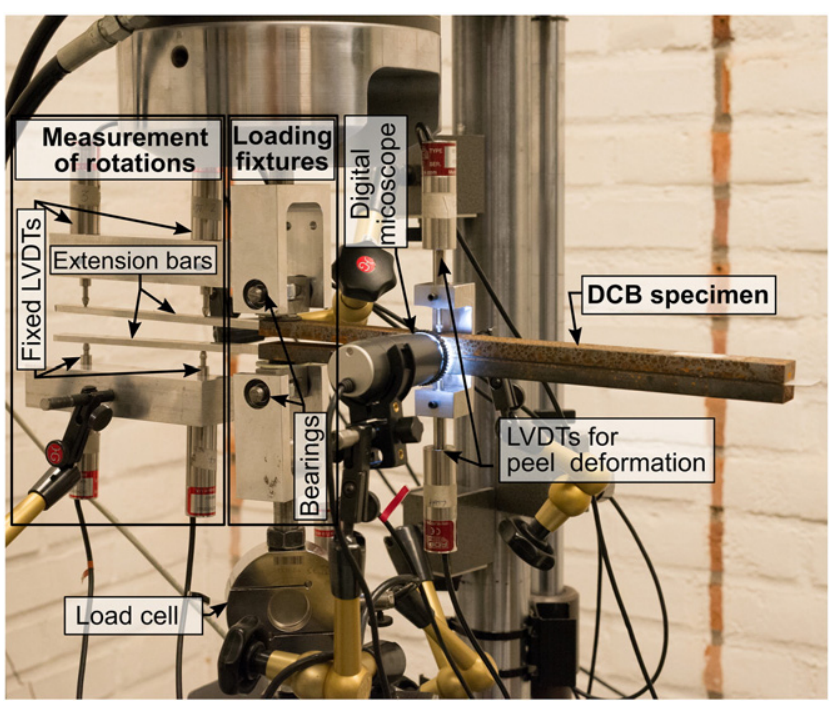

Fig. 5. DCB test setup with a deformed specimen.

peeling deformation at the crack tip was measured using two vertically placed LVDTs on the outside of the specimen above and below the crack tip. This procedure is shown in [9] to capture the peeling deformation of the adhesive layer with sufficient accuracy. In addition, a digital microscope with a calibrated scale was used to take photos every $5 \mathrm{~s}$ to monitor the damage progress at the crack tip. The LVDTs had a resolution of $1 \mu \mathrm{m}$. A load cell with a capacity of $5 \mathrm{kN}$ was used to measure the applied force. The tests were conducted in the displacement-control mode with the constant cross head speed of $0.5 \mathrm{~mm} / \mathrm{min}$ to achieve quasi-static loading.

2.2.2.2. Mode II fracture energy. Using the J-integral approach, the energy release rate of a symmetrically loaded ENF specimen $(d=L / 2)$ with equal adherend and adhesive width $(B=b)$ was obtained by Leffler et al. [11] as:

$J_{I I} \approx \frac{9}{16} \frac{F^{2} a^{2}}{E b^{2} h^{3}}+\frac{3}{8} \frac{F v}{b h}$

The first term is equivalent to the one derived by Russel and Street [56] based on Euler-Bernoulli beam theory. The second term is to take into account the flexibility of the adhesive layer, which, as shown in [57], can give a substantial contribution to the fracture energy of tough adhesives. For specimens with unequal adherend and adhesive width $(B \neq b)$, Eq. (5) can be modified using the approach presented in [58]. Although, this equation can be used to obtain continuous development of $J$, some conditions must be met for its applicability. These conditions are that the adherends must remain linear-elastic during the experiment and that the fracture process zone must be accommodated between the crack tip and the loading point, i.e. region denoted $c$ in Fig. 3(b). It is shown by Walander et al. [10] that these conditions can lead to unreasonably large specimens and testing equipment. To work around this problem, Stigh and Biel [17] used a different counter-clockwise path for the path-independent J-integral and obtained:

$J_{I I}=\frac{F}{b}\left[\frac{d}{L} \sin \left(\theta_{l}\right)-\sin \left(\theta_{f}\right)+\left(1-\frac{d}{L}\right) \sin \left(\theta_{r}\right)\right]$

As can be seen, Eq. (6) does not contain any term related to the stiffness of the adherends and only the rotations are included. Moreover, as elaborately discussed in [10], using Eq. (6) allows the adherends to deform plastically with the condition that unloading from a plastic region is avoided (i.e. nonlinear-elastic). This comes with distinct advantages such as smaller specimen size and testing equipment. It is shown by
Walander [59] that Eq. (6) can be used with local plastic deformation provided that no cross-section is fully yielded before cracking of the adhesive front. For the case of large-scale yielding, Goutianos and Sørensen [60] have recently presented a method to analyse DCB specimens loaded with bending moments. In addition, the accuracy of methods with applied forces and large-scale yielding is studied by Marzi et al. [61]. A requirement of using Eq. (6) is the measurement of the rotations at the point of load application and over the supports. The apparatus depicted in Fig. 6 was developed for this purpose. The system of rotation measurement was based on a similar method to the one used for DCB specimens, which included two vertical mounted LVDTs and an attached T-shape bar per measurement point. In addition, the shear deformation at the crack tip was measured using an LVDT mounted on a fixture attached to the adherends. Similar to the DCB experiment, the crack tip was photographed every $5 \mathrm{~s}$ using a microscope. The tests were conducted in the displacement-control mode with a load-point displacement rate of $0.5 \mathrm{~mm} / \mathrm{min}$. The accuracy of the measurements and the negligible compliance of the rig were confirmed by testing a solid steel beam.

\subsubsection{Derivation of cohesive laws}

Having captured the development of $J$ during an experiment and provided that the peel or shear deformations at crack tip are continuously measured, Eq. (3) can be used to obtain the stress-deformation relationships, i.e. cohesive laws. However, differentiation of $J$ with respect to $w$ or $v$ is very sensitive to the noise inherited in experimental measurements. Therefore, the $J$ versus pure-mode deformations $(\delta=$ $w$ or $v$ ) were first fitted to a Prony-series with the form:

$J(\delta)=J_{c} \sum_{i=1}^{n} A_{i} e^{-\frac{n}{i \delta^{c}} \delta}$

where

$A_{n}=-n\left(A_{1}+\frac{A_{2}}{2}+\frac{A_{3}}{3}+\ldots+\frac{A_{n-1}}{n-1}\right)$

where $J_{c}$ is the critical fracture energy, $\delta_{C}$ is the critical separation and the constants $A_{i}$ were obtained using a least-square method. The defined constrain for $A_{n}$ was applied in order to have zero stress at zero displacement, that is a physical condition. In this study, it was observed that increasing the number of terms to $>16$ did not generally affect the quality of the fits, and thereby $n=16$ was chosen. The fitted curves were then differentiated numerically to obtain the cohesive laws. In order to assess the accuracy of this method, the direct derivative of the experimentally obtained $J-\delta$ curve was compared with that of the fitted one. Fig. 7 shows an example of this comparison for an ENF specimen. As can be seen, in addition to the eliminated measurements'

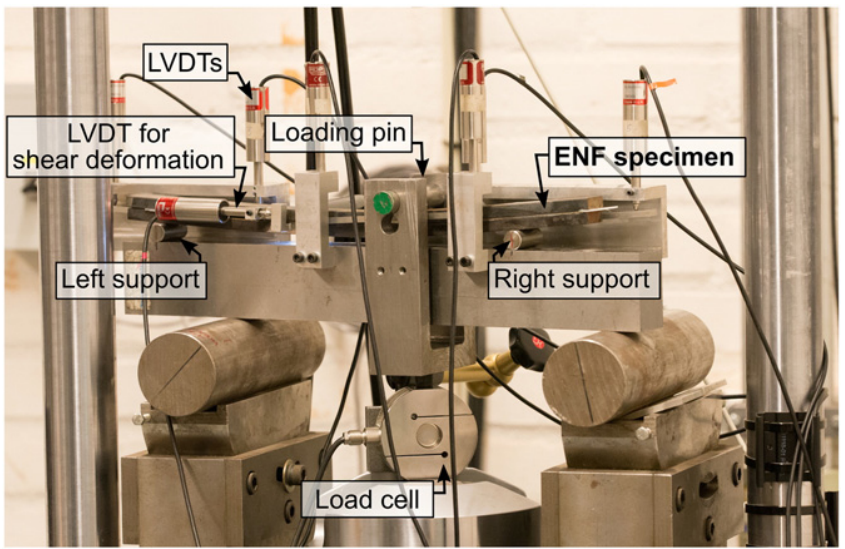

Fig. 6. ENF test setup with a deformed specimen. 


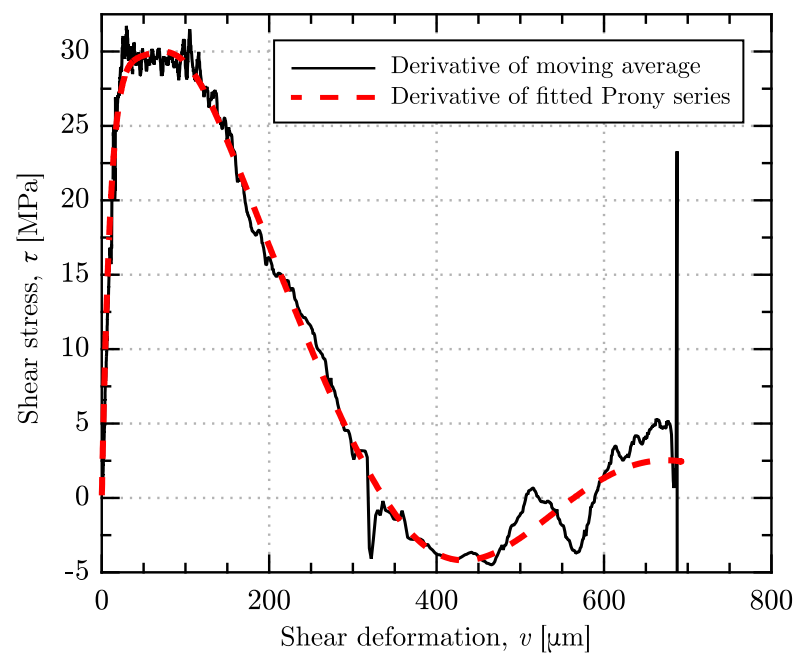

Fig. 7. Comparison of the cohesive laws of EC1 specimen obtained using the derivation of experimental data and a fitted Prony series.

noise, the cohesive law is accurately represented by the adapted method.

\subsection{Environmental conditioning}

In order to address the effects of moisture on cohesive laws, three exposure conditions were used. The ageing temperature was chosen as $45^{\circ} \mathrm{C}$ to accelerate moisture diffusion. This temperature is $10{ }^{\circ} \mathrm{C}$ below the adhesive glass transition temperature and is believed to safely accelerate moisture diffusion without activating unwanted reactions $[49,62]$. The exposure conditions were:

(i) 45DW: immersion in distilled water at $45^{\circ} \mathrm{C}$,

(ii) $45 \mathrm{SW}$ : immersion in $5 \% \mathrm{NaCl}$ salt-water at $45^{\circ} \mathrm{C}$,

(iii) 45RH: exposure to $95 \%$ relative humidity at $45{ }^{\circ} \mathrm{C}$.

For the first two ageing conditions, open-face specimens were put in immersion tanks at $45^{\circ} \mathrm{C}$. The $45 \mathrm{RH}$ condition was achieved by using a fan-assisted environmental chamber. Six DCB and six ENF specimens were aged at each condition. The time to saturation was estimated using transient 3D mass diffusion analysis as described in [49]. The analysis showed that the moisture content of the specimens, irrespective of the ageing condition, would exceed $90 \%$ of their corresponding moisture saturation limit upon ageing for 60 days. To account for small adhesive layer thickness- or exposure temperature variations, the specimens were aged for 90 days. Afterwards, all the aged specimens were completed, i.e. the second steel adherend was bonded, following the procedure described in Section 2.1.

For each condition, three DCB and three ENF specimens were tested after ageing for 90 days, and the rest of the aged specimens were moved to an environmental chamber to be subjected to additional freeze-thaw cycling. In addition, three unaged DCB and three unaged ENF specimens were subjected to the freeze-thaw cycles. It should be noted that, as all the open-face specimens were completed prior to freeze-thaw cycling, moisture desorption from wet specimens during thawing was minimized. The environmental chamber used for freeze-thaw cycling was programmed to continuously repeat a thermal cycle as illustrated in Fig. 8. In this regard, the specimens were thawed for $6 \mathrm{~h}$ at $+20^{\circ} \mathrm{C}$, then the temperature was ramped down at a constant rate of $1{ }^{\circ} \mathrm{C} / \mathrm{min}$ to $-20{ }^{\circ} \mathrm{C}$ at which they underwent $6 \mathrm{~h}$ of freezing. The freezethawed specimens were tested after completion of 250 cycles.

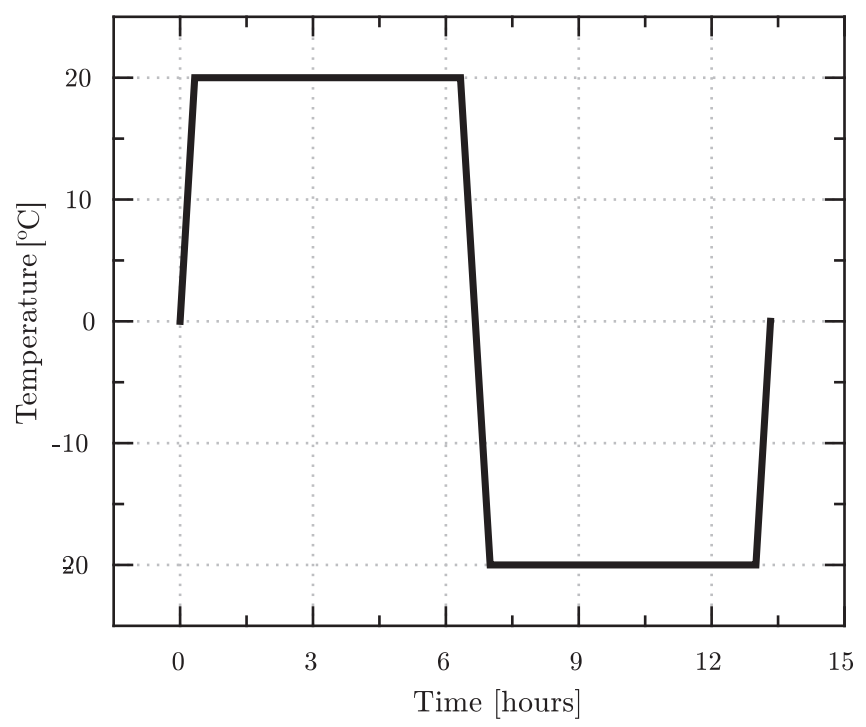

Fig. 8. Illustration of a freeze-thaw cycle.

\section{Finite element analysis}

The experimentally obtained cohesive law parameters were given as input to simulate the DCB and ENF tests. The simulation results in terms of force versus force-line displacement were then compared with those obtained from the experiments. These comparisons serve as a tool to check the accuracy of the experimentally obtained cohesive-laws. By including the secondary adhesive layer in the model, its effect on the obtained cohesive laws can also be evaluated, see Section 4.1.1. The FEanalysis is also used to verify the assumption of no cross-sectional unloading from a plastic state for the ENF specimens suspected to undergo local yielding. In this regard, the commercial software Abaqus ${ }^{\circ}$ 6.13 was used. Three-dimensional modelling was performed to control the distribution of damage through the width of the adhesive layer [63]. In this regard, a non-uniform damage distribution profile, e.g. thumbnail shape, is undesirable since it indicates severe plastic deformation of the adherends or insufficient width of specimens [52]. In addition, the constructed 3D models were used to verify the accuracy of the used equations for specimens with unequal width of adherend and adhesive (Section 4.1.1). The geometries were modelled as 3D objects according to the dimensions listed in Table 3. Plastic response of the steel adherends was modelled using tabulated data obtained from tensile coupon tests. The adhesive materials were modelled as linear-elastic with the properties listed in Table 1 and Table 2. All the continuum elements were modelled with 3D 8-node brick elements with reduced integration (C3D8R). A layer of cohesive elements with $0.02 \mathrm{~mm}$ thickness were placed in the centre of the primary adhesive layer as a predefined crack path. In addition to the Abaqus inherent COH3D8 cohesive elements with a bi-linear cohesive-law, potential-based cohesive

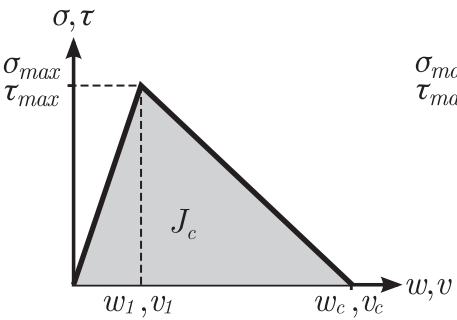

(a)

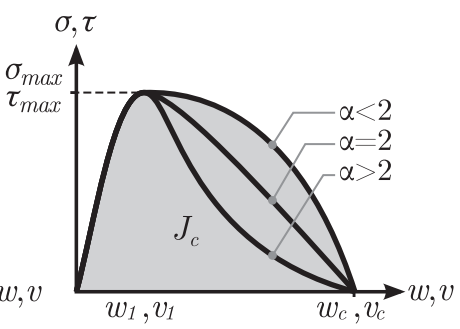

(b)
Fig. 9. The Mode I cohesive laws used in the FE analysis: (a) bi-linear cohesive-law, (b) PPR (Park-Paulino-Roesler) potential-based cohesive-law. 


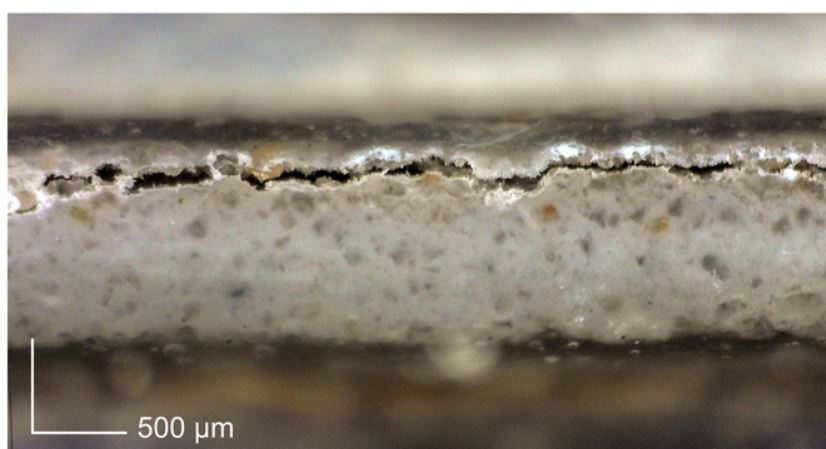

(a)

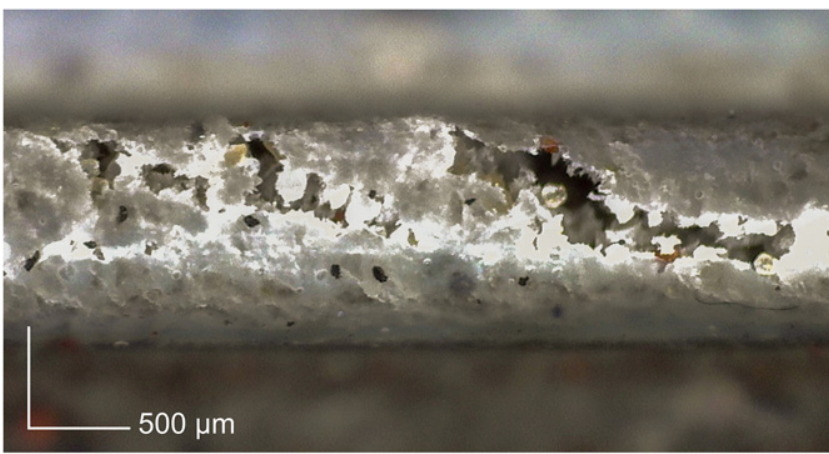

(b)

Fig. 10. Photographs of the crack tip region of adhesive layer: (a) DCB specimen with peeling crack, (b) ENF specimen with shear crack. elements developed by Spring and Paulino [64] were used, see Fig. 9. The latter elements, which were implemented using a user element, allow for a more realistic shape of cohesive-law.

\section{Results and discussion}

\subsection{Control specimens}

The failure surfaces of all the specimens presented in this study were carefully analysed after the experiments. This was done by separating the two adherends and examining the fracture surfaces close to crack tip region. It was observed that all the control specimens failed cohesively within the adhesive layer. Fig. 10 depicts microscopic photographs of the developed peeling and shear cracks in the adhesive layer of the control DCB and ENF specimens, respectively. As can be seen, the cracks are within the primary adhesive layer, thereby confirming the quality of the bonds and the strength of the secondary adhesive material. As can be seen in Fig. 10(b), the deformed shape of the cracked adhesive layer subjected to pure Mode-II loading reveals normal opening in addition to the shear deformation. This observation has been reported by some researchers for the ENF configuration [11,50,65]. Recently Sørensen and Goutianos [66] developed a model for delamination of composites where a similar phenomenon is observed. A requirement of this model is the measurement of the normal opening at crack tip in ENF specimens. In the current study, the normal opening of ENF specimens was not measured and therefore this effect could not be considered. However, as the inaccuracy caused by this phenomenon would affect all the measurements to the same extent, the comparative assessments are expected to remain valid.

The experimental and numerical results of the control specimens are plotted in Fig. 11. It is apparent from the force vs. force-line displacement
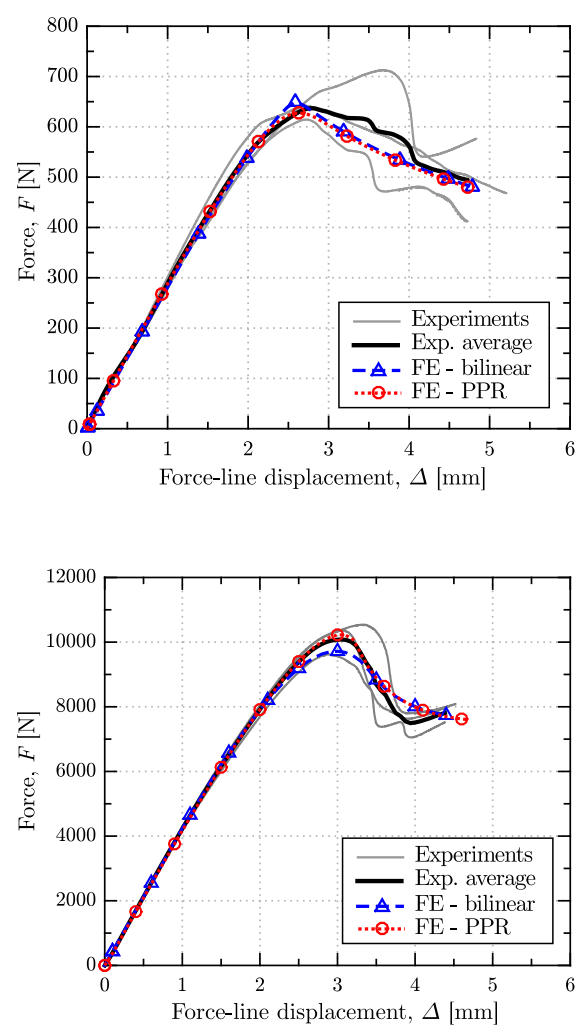

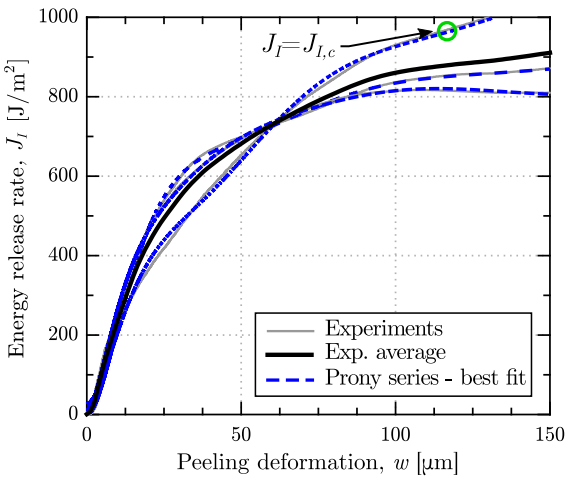

(a)

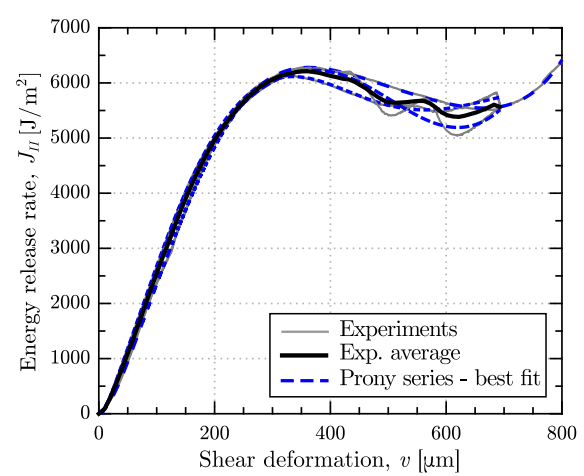

(b)
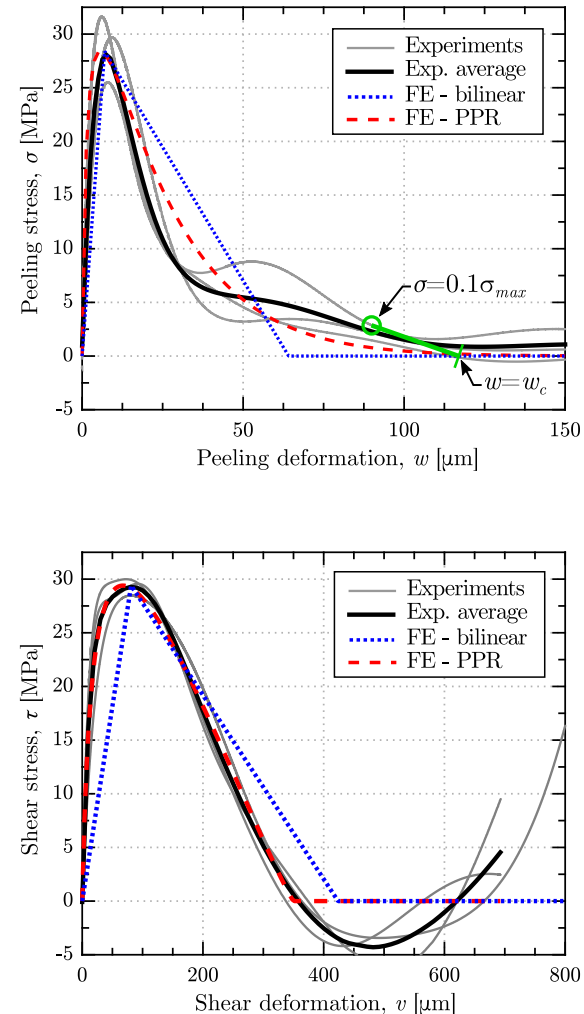

Fig. 11. Experimental and FE predicted response of control DCB and ENF specimens: (a) DCB results corresponding to Mode I, (b) ENF results corresponding to Mode II. 
curves of both DCB and ENF specimens that the applied force drops after reaching a maximum load. Assessment of the crack tip photographs taken by the microscope revealed the appearance and propagation of cracks right after the peak load is reached. The developments of Mode I and Mode II fracture energy with respect to peeling or shear deformation for control specimens are presented in Fig. 11(a) and (b), respectively. The corresponding cohesive laws of the control specimens were derived by differentiation of these curves with respect to the peeling or shear deformation, as described in Section 2.2.3, and are included in Fig. 11. As can be seen, for Mode I loading, the peak stress, $\sigma_{\max }$, is reached at peeling deformations of $w_{1}=8 \pm 1 \mu \mathrm{m}$. In comparison, the corresponding deformation at peak shear stress, $\tau_{\max }$, is considerably larger and is around $v_{1}=81 \pm 8 \mu \mathrm{m}$. From this point on, an increase in the applied load would result in irreversible damage until crack initiation at critical deformation. For the sake of consistency, the critical deformation, $w_{c}$ or $v_{c}$, is obtained by extending the decaying part of the cohesive law curve using the tangent line at a stress-level equal to $10 \%$ of the peak stress. The deformation at the intercepting point with zero stress is taken as critical deformation. As an example, this is illustrated for one of the DCB specimens (DC2) in Fig. 11(a): $\sigma$-w plot. Using this definition for critical deformation, the corresponding fracture energy was defined as the critical fracture energy, $J_{c}$. Another observation from Fig. 11(b): $\tau-v$ plot is the negative shear stresses for deformations exceeding the critical shear deformation. Given that the cohesive laws are obtained by differentiation of the energy release rate curves, this observation is linked with the decrease of $J_{I I}$ after the maximum is reached. The authors believe that the decreasing fracture energy (and consequently the negative stresses) might be an effect of creation of a sharper crack tip during crack propagation. This is mainly because no sharp cracks were created at the start of adhesive layer to obtain initiation fracture properties that are of higher value in engineering applications.

As mentioned in Section 3, the simulation results of the DCB and ENF tests can be used to ascertain the accuracy of the approximated cohesive laws based on the experiments. As input to the FE analysis, the triangular and PPR cohesive laws, best representing the experimental ones, were obtained for each series. The former was constructed by using the average peak stress and its corresponding deformation as well as the average critical fracture energy. Due to more flexibility of the PPR cohesive law, it was fitted to the experimental average cohesive law using non-linear regression analysis with the average critical fracture energy as a constant. The corresponding cohesive laws for each loading mode are added with dotted and dashed lines to the stress-deformation plots in Fig. 11. It can be noted from this figure that the experimental curves are more accurately represented by the PPR cohesive laws.

Fig. 12 depicts the modelled geometries of the tested specimens as well as the contours of Mises stresses in the steel adherends at the time of crack initiation. The figure also presents the state of predicted damage in the adhesive layer of each specimen using the triangular cohesive law. As illustrated, the length of the damage process zone is considerably larger for the case of Mode II loading. For both cases, the lengths of damage process zones are larger than the height of the adherends and several orders of magnitude larger than adhesive layer thickness. This is more significant for the case of Mode II loading. It is interesting to note that, the length of the K-dominant zone for adhesively bonded DCB specimens is derived equal to $t_{a} / 40$ by Wang et al. [7]. Therefore, the K-dominant zone is calculated equal to $0.03 \mathrm{~mm}$ for the DCB configuration used in this study which is significantly smaller than the length of the damage process zone $(11 \mathrm{~mm})$. This underlines that the LEFM approach is not applicable for fracture characterization of the adhesive material used in this study. Furthermore, given that the ENF specimen was not symmetrically loaded, it can accommodate such a long damage process zone between the loading point and the crack tip. It is also worthwhile noting that the steel adherends have undergone some yielding while no cross section is fully yielded. The predicted force vs. force-line displacement responses are compared with the experimental ones in the plots on the left side of Fig. 11. As can be seen, the predicted curves concur well with the experiments. Remarkably, the responses close to the peak loads are precisely predicted using the FE models incorporating the PPR cohesive laws. Nevertheless, the difference between the overall predicted responses using triangular and PPR cohesive laws is found insignificant.

\subsubsection{Effect of the secondary adhesive layer}

Having accurately predicted the responses of the DCB and ENF control specimens, the constructed FE models can be further utilized to investigate the effects of the secondary adhesive layer. This can be achieved by simulating the whole experiment with various thicknesses for the secondary adhesive layer. As the correct $J_{c}$ and cohesive laws are known a priori, evaluation of the simulated experiments can manifest the effect of secondary adhesive layer. In this regard, the simulation results were post processed to calculate the rotations of the adherends, crack tip displacement, and reaction forces. Next, the energy release rate was calculated using Eq. (4) or (6). As a final step, the cohesive law was obtained by differentiating the energy release rate with respect to the crack tip deformation. Fig. 13(a) shows the obtained energy release rate for the ENF specimens with secondary adhesive layer thickness of $0,0.05,0.6$ and $1.2 \mathrm{~mm}$. The results of the ENF specimen are presented here due to its high load capacity, and thereby high stresses in the adhesives, which would intensify the possible effects of the secondary adhesive layer. As the back calculated critical fracture energies are equal to the defined value in the FE model, the accuracy of the used equations for specimens with unequal width of adherends and adhesives in verified. This figure reveals that the obtained critical fracture energy is virtually unaffected by the thickness of the secondary adhesive

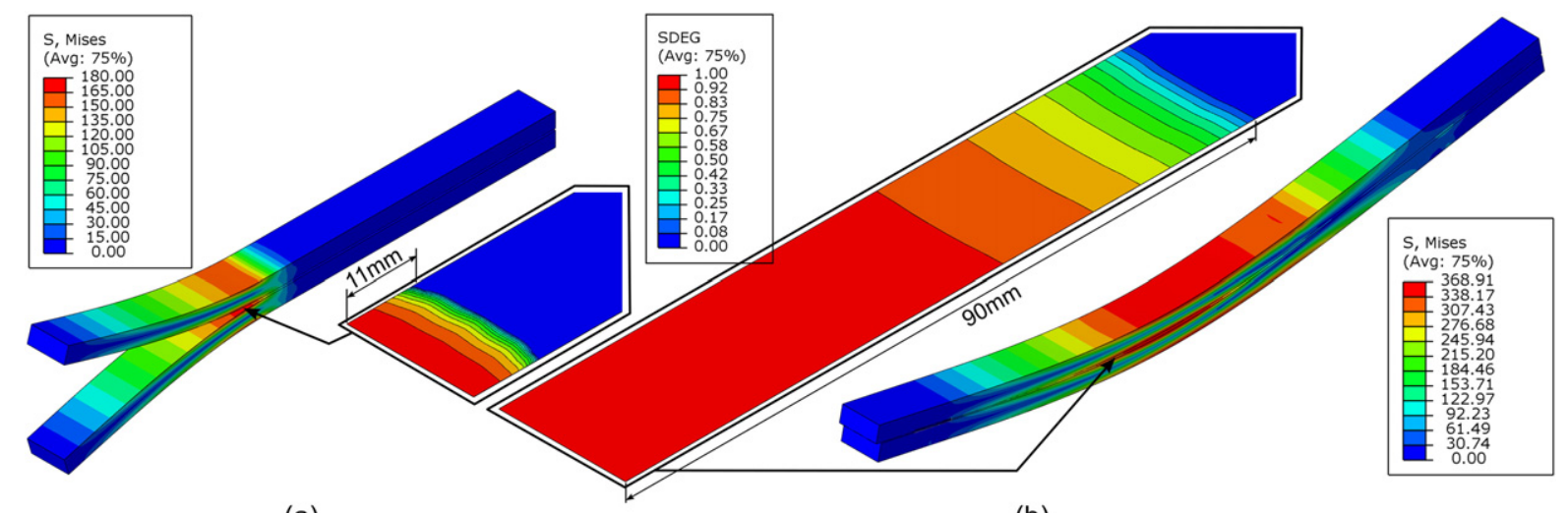

(a)

(b)

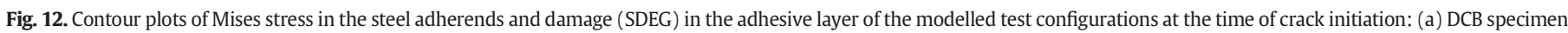
(deformation is magnified 20 times), (b) ENF specimen (deformation is magnified 5 times). 


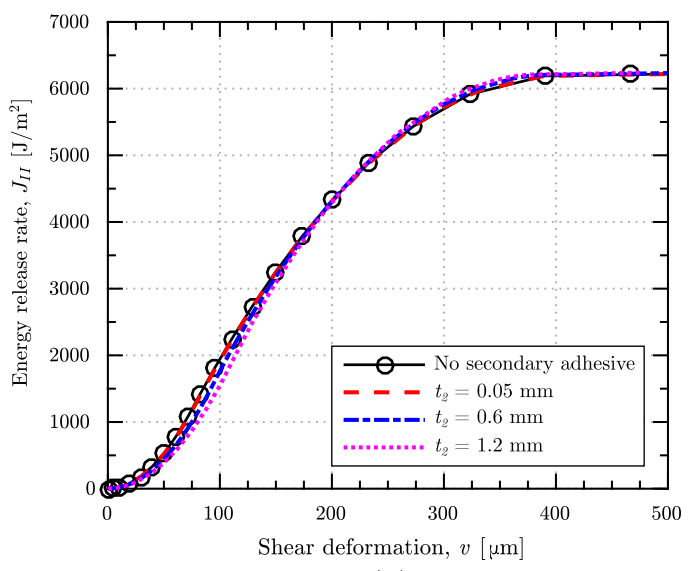

(a)

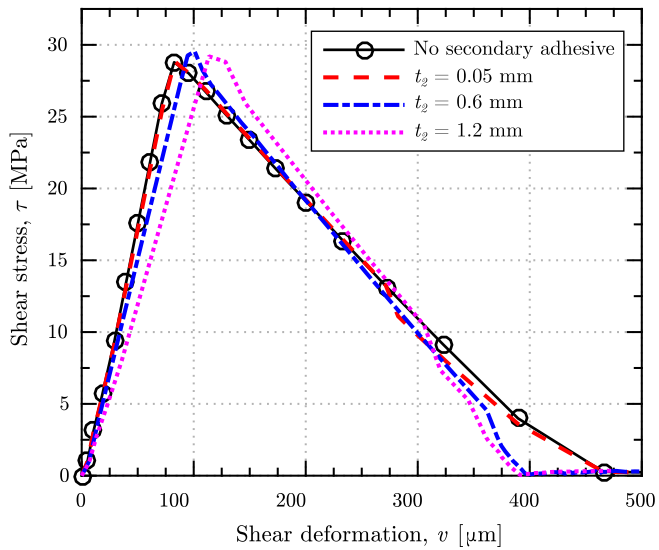

(b)

Fig. 13. Effect of the secondary adhesive layer thickness $\left(t_{2}\right)$ on: (a) Mode II energy release rate, (b) Mode II cohesive law.

layer. As shown in Fig. 13(b), the cohesive laws are slightly affected by large variations of this parameter. The results clearly indicate that as the secondary adhesive layer gets thicker, the error in measurement of cohesive law becomes larger. Nevertheless, for a very thin adhesive layer, such as the one used in this study, this effect is negligible. It should, however, be clearly stated here that the reasoning presented above is only valid if the secondary adhesive layer itself is not damaged. This can be ensured by using relatively stronger and less stiff secondary adhesive compared with the primary adhesive material.

\subsection{Moisture-dependent cohesive laws}

Similar to the control specimens, the failure mode of the specimens exposed to wet conditions were cohesive, i.e. in the adhesive layer. This observation suggests that the interfacial strength of the bond between the primary adhesive and steel remained intact after three months of exposure to wet conditions. With this in mind, the changes of shape of cohesive laws can be attributed to the moisture content of the adhesive material at the time of testing. The moisture saturation content of this adhesive is reported by the authors in [49] to range from $1.1 \%$ to $1.77 \%$ depending on the humidity level and solution type of the exposure condition. Fig. 14 shows the obtained cohesive laws for the primary adhesive with varying moisture content. For each ageing condition, the moisture content of the adhesive material at the time of testing $\left(M_{t}\right)$ was estimated by means of a mass-diffusion FE analysis, which is thoroughly described in [49]. The moisture content values $\left(M_{t}\right)$ are indicated in the legend of each plot in Fig. 14. These plots are arranged with an ascending order of the adhesive moisture content from left to right. As can be seen from the plots, the scatter of the obtained curves is generally negligible except for the case of the Mode I cohesive laws at 45RH. Further assessment of these specimens revealed no particular defects or abnormalities, hence they were not excluded from the analysis. Table 4
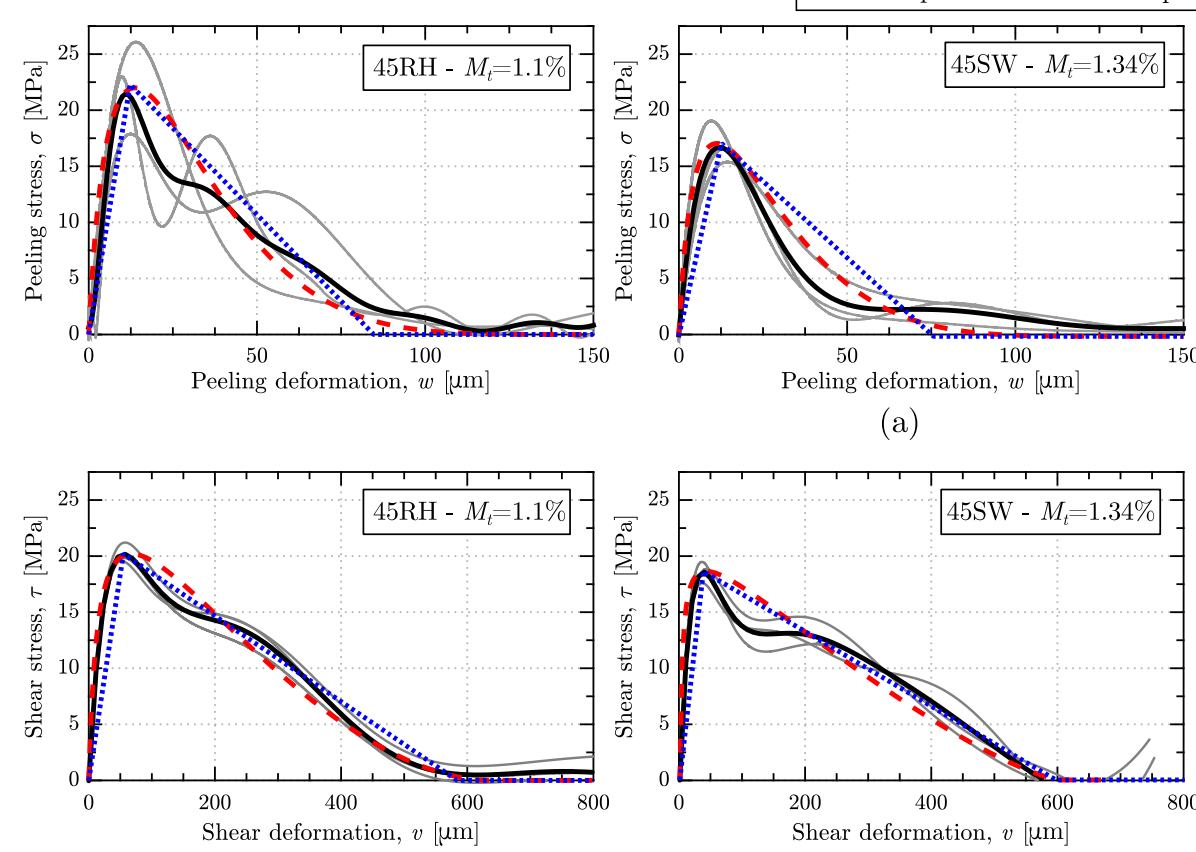

(b)

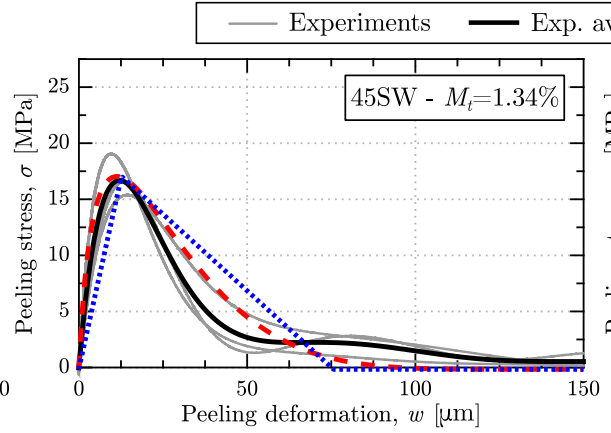

(a)

Fig. 14. Moisture dependency of the cohesive laws of the tested epoxy adhesive: (a) Mode I cohesive laws, (b) Mode II cohesive laws. 
Table 4

Experimentally obtained cohesive-law parameters (cf. Fig. 9) for Mode I and Mode II loading as a function of moisture content (Avg: mean value, SD: standard deviation).

\begin{tabular}{|c|c|c|c|c|c|c|c|c|c|c|c|}
\hline \multirow[t]{2}{*}{ Condition } & \multirow[t]{2}{*}{ Moisture content, $M_{t}[\%]$} & \multicolumn{5}{|c|}{ Mode I (DCB configuration) } & \multicolumn{5}{|c|}{ Mode II (ENF configuration) } \\
\hline & & Specimen ID & $\begin{array}{l}J_{I}^{c} \\
{\left[\mathrm{~J} / \mathrm{m}^{2}\right]}\end{array}$ & $\begin{array}{l}\sigma_{\max } \\
{[\mathrm{MPa}]}\end{array}$ & $\begin{array}{l}w_{c} \\
{[\mu \mathrm{m}]}\end{array}$ & $\begin{array}{l}w_{1} \\
{[\mu \mathrm{m}]}\end{array}$ & Specimen ID & $\begin{array}{l}J_{I I}^{c} \\
{\left[\mathrm{~J} / \mathrm{m}^{2}\right]}\end{array}$ & $\begin{array}{l}\tau_{\max } \\
{[\mathrm{MPa}]}\end{array}$ & $\begin{array}{l}v_{c} \\
{[\mu \mathrm{m}]}\end{array}$ & $\begin{array}{l}v_{1} \\
{[\mu \mathrm{m}]}\end{array}$ \\
\hline \multirow[t]{4}{*}{ Control } & \multirow[t]{4}{*}{0} & DC1 & 864 & 29.7 & 141 & 9 & EC1 & 6127 & 30 & 339 & 72 \\
\hline & & DC2 & 966 & 23.2 & 118 & 8 & $\mathrm{EC} 2$ & 6290 & 28.5 & 361 & 80 \\
\hline & & DC3 & 820 & 31.6 & 112 & 7 & EC3 & 6254 & 29.6 & 370 & 91 \\
\hline & & Avg. $( \pm S D)$ & $883( \pm 61)$ & $28.2( \pm 3.6)$ & $124( \pm 13)$ & $8( \pm 1)$ & Avg. $( \pm S D)$ & $6224( \pm 70)$ & $29.4( \pm 0.6)$ & $357( \pm 13)$ & $81( \pm 8)$ \\
\hline \multirow[t]{4}{*}{$45 \mathrm{RH}$} & \multirow[t]{4}{*}{1.1} & DR1 & 952 & 17.9 & 112 & 13 & ER1 & 5765 & 19.6 & 556 & 51 \\
\hline & & DR2 & 956 & 23 & 150 & 10 & ER2 & 5507 & 19.8 & 575 & 57 \\
\hline & & DR3 & 914 & 26.1 & 146 & 14 & ER3 & 6389 & 21.2 & 600 & 57 \\
\hline & & Avg. $( \pm S D)$ & $941( \pm 19)$ & $22.3( \pm 3.3)$ & $136( \pm 17)$ & $12( \pm 2)$ & Avg. $( \pm S D)$ & $5988( \pm 370)$ & $20.2( \pm 0.7)$ & $577( \pm 18)$ & $55( \pm 3)$ \\
\hline \multirow[t]{4}{*}{ 45SW } & \multirow[t]{4}{*}{1.34} & DS1 & 561 & 19.2 & 129 & 10 & ES1 & 5399 & 19.4 & 611 & 35 \\
\hline & & DS2 & 731 & 15.5 & 141 & 15 & ES2 & 5581 & 18.8 & 561 & 42 \\
\hline & & DS3 & 625 & 16.8 & 113 & 13 & ES3 & 5651 & 17.6 & 563 & 35 \\
\hline & & Avg. $( \pm S D)$ & $625( \pm 75)$ & $17.2( \pm 1.5)$ & $128( \pm 12)$ & $13( \pm 2)$ & Avg. $( \pm S D)$ & $5544( \pm 106)$ & $18.6( \pm 0.7)$ & $578( \pm 23)$ & $37( \pm 3)$ \\
\hline \multirow[t]{4}{*}{ 45DW } & \multirow[t]{4}{*}{1.59} & DD1 & 698 & 19.6 & 106 & 8 & ED1 & 5449 & 21.8 & 654 & 36 \\
\hline & & DD2 & 772 & 20 & 118 & 11 & ED2 & 6681 & 20.2 & 688 & 34 \\
\hline & & DD3 & 634 & 17.6 & 131 & 13 & ED3 & 6690 & 23.4 & 576 & 41 \\
\hline & & Avg. $( \pm S D)$ & $701( \pm 56)$ & $19.1( \pm 1.0)$ & $118( \pm 10)$ & $11( \pm 2)$ & Avg. $( \pm S D)$ & $6273( \pm 583)$ & $21.8( \pm 1.3)$ & $639( \pm 47)$ & $37( \pm 3)$ \\
\hline
\end{tabular}

lists the cohesive law parameters for the adhesive layers of all the specimens subjected to wet ageing conditions as well as the control specimens.

The cohesive laws used as input for the FE analysis were constructed based on the average of experimental cohesive laws, and are added to the plots in Fig. 14. In general, the FE-predicted force-displacement curves were found in good agreement with the experiments. However, as also reported for the control specimens, the predictions using the PPR cohesive laws better matched the experiments. This was more noteworthy for the case of ENF specimens due to their significantly larger damage process zone.

Fig. 15 shows the effects of moisture on the shape of the obtained average cohesive laws for Mode I and Mode II loading. As can be seen from Fig. 15(a), the initial slopes and peak stresses of the Mode I cohesive laws of the wet adhesives are reduced compared with the dry one. This reduction appears to be the largest for ageing in saltwater. Interestingly, a different behaviour for the changes of the modulus of elasticity and tensile strength of the same adhesive exposed to the same wet ageing conditions was reported in [49] where the authors showed less damaging effects of saltwater compared with distilled water or vapour. This conclusion was derived based on the results of tensile dog-bone specimens. This discrepancy provides convincing evidence that although the results obtained from simple tensile tests could be useful for linear analysis, they cannot be extended to damage simulation and strength prediction. This is in line with the results concluded by Li et al. [67] who found that the bulk tensile tests are inappropriate to determine the temperature influence on the peak stress of cohesive laws.

As shown in Fig. 15(b) for Mode II loading, the cohesive laws of the wet adhesives are found to be very similar in shape irrespective of the ageing condition or moisture content. In this regard, the initial stiffness moduli are found almost unchanged after ageing. Compared with the dry adhesive, ageing in wet conditions reduced the peak stresses and caused the critical deformations to increase. As these behaviours are rather different from those observed for Mode I cohesive laws, caution must be excursed when extending the results of one loading mode to the others.

\subsection{Effect of combined moisture and freeze-thaw cycles}

Cohesive failure was also the observed failure mode for the majority of specimens subjected to additional freeze-thaw cycles. The only exception was the interfacial debonding failure of the specimens initially aged in 45DW. This observation can be attributed to the fact that ageing

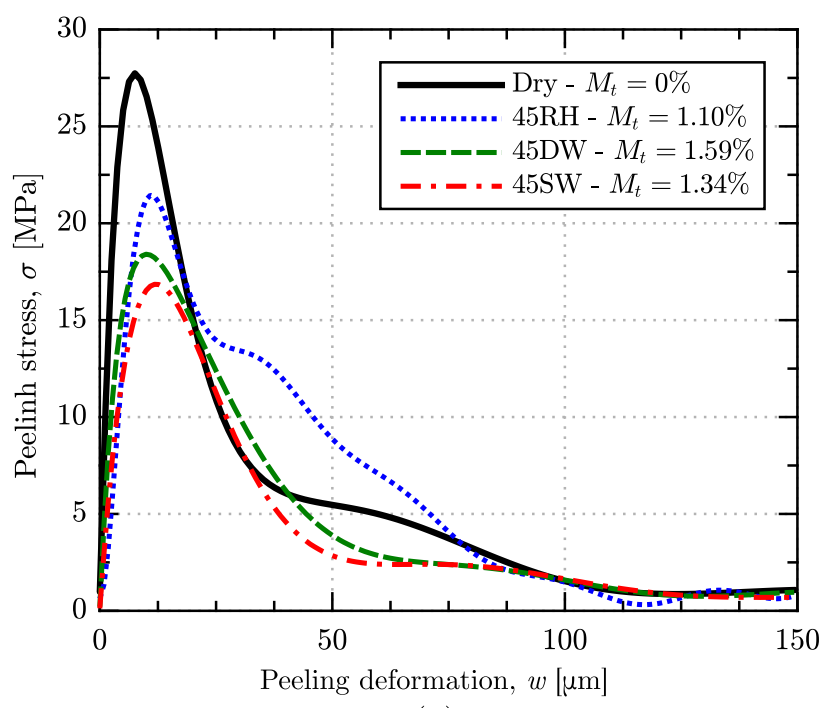

(a)

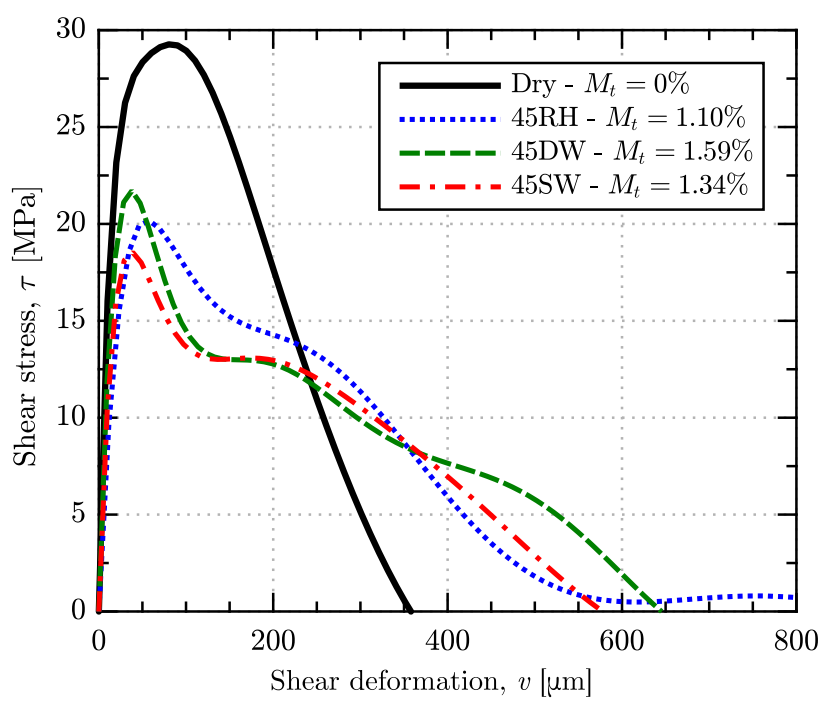

(b)

Fig. 15. Comparison of the obtained cohesive laws for wet ageing conditions: (a) Mode I, (b) Mode II. 

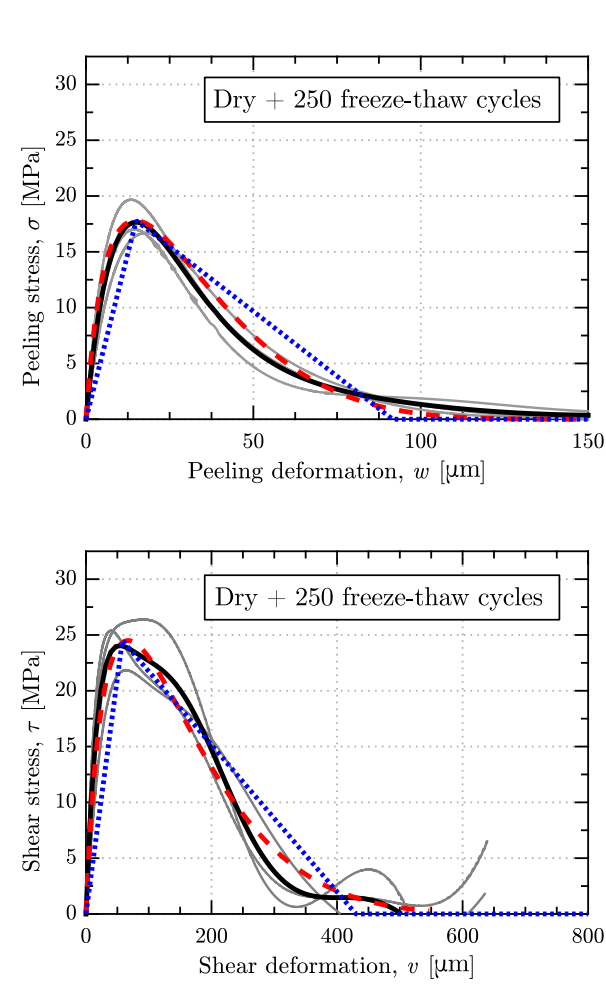

Fig. 16. Effect of combined moisture and freeze-thaw cycling on the cohesive laws of the tested epoxy adhesive: (a) Mode I cohesive laws, (b) Mode II cohesive laws. in 45DW led to the highest moisture content of the adhesive layer among the tested environments [49]. The presence of relatively high amounts of moisture for an extended time and the induced stresses caused by its volumetric expansion could have reduced the interfacial strength leading to interfacial debonding. As the aim of this paper is to characterize the effects of environmental conditioning on the cohesive laws of the adhesive material, these specimens were excluded from further analysis.

The cohesive laws of the adhesive material subjected to freeze-thaw cycles in the presence/absence of moisture are presented in Fig. 16 and Table 5. Similar to previous section, the FE simulations using the constructed cohesive laws provided reasonable predictions of the experiments. As for the experimental results, generally, the shapes of the cohesive laws obtained for each exposure scenario follow similar trends with insignificant scatter. Therefore, the average curves of the experimental data are used for further comparisons related to the effects of each environmental exposure. Such comparisons are illustrated in Fig. 17 for Mode I and Mode II loading. It is apparent from Fig. 17(a) that the initial stiffness and peak stress of the cohesive laws in Mode I are reduced after freezethaw cycling. Interestingly, such reductions are also observed for the specimens with a dry adhesive material. This highlights the damaging effects of freeze-thaw cycles alone on Mode I cohesive laws. In comparison, the initial stiffness for Mode II loading is found unaltered irrespective of the initial ageing condition or the presence of moisture. Remarkable reduction of peak stresses, however, are only observed for the dry specimens, which further highlights the isolated effects of freeze-thaw cycles. In addition, as also concluded for wet ageing conditions, freezethaw cycles can alter the cohesive laws differently depending on the loading Mode. Therefore, the generalization of the cohesive laws for all loading modes can be erroneous.

Table 5

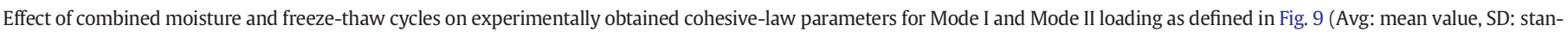
dard deviation).

\begin{tabular}{|c|c|c|c|c|c|c|c|c|c|c|}
\hline \multirow[t]{2}{*}{ Condition } & \multicolumn{5}{|c|}{ Mode I (DCB configuration) } & \multicolumn{5}{|c|}{ Mode II (ENF configuration) } \\
\hline & Specimen ID & $\begin{array}{l}J_{I}^{c} \\
{\left[\mathrm{~J} / \mathrm{m}^{2}\right]}\end{array}$ & $\begin{array}{l}\sigma_{\max } \\
{[\mathrm{MPa}]}\end{array}$ & $\begin{array}{l}w_{c} \\
{[\mu \mathrm{m}]}\end{array}$ & $\begin{array}{l}w_{1} \\
{[\mu \mathrm{m}]}\end{array}$ & Specimen ID & $\begin{array}{l}J_{I I}^{c} \\
{\left[\mathrm{~J} / \mathrm{m}^{2}\right]}\end{array}$ & $\begin{array}{l}\tau_{\max } \\
{[\mathrm{MPa}]}\end{array}$ & $\begin{array}{l}v_{c} \\
{[\mu \mathrm{m}]}\end{array}$ & $\begin{array}{l}v_{1} \\
{[\mu \mathrm{m}]}\end{array}$ \\
\hline \multirow[t]{4}{*}{ Dry + freeze-thaw } & DFC1 & 770 & 17 & 182 & 14 & EFC1 & 4813 & 25.4 & 393 & 40 \\
\hline & DFC2 & 824 & 19.7 & 108 & 13 & EFC2 & 5299 & 26.4 & 322 & 70 \\
\hline & $\mathrm{DFC} 3$ & 811 & 16.7 & 126 & 18 & EFC3 & 5054 & 21.8 & 418 & 64 \\
\hline & Avg. $( \pm S D)$ & $802( \pm 23)$ & $17.8( \pm 1.3)$ & $139( \pm 31)$ & $15( \pm 2)$ & Avg. $( \pm S D)$ & $5055( \pm 198)$ & $24.5( \pm 2.0)$ & $378( \pm 58)$ & $58( \pm 13)$ \\
\hline \multirow[t]{4}{*}{$45 \mathrm{RH}+$ freeze-thaw } & DFR1 & 779 & 16.2 & 103 & 15 & EFR1 & 5889 & 33.1 & 432 & 37 \\
\hline & DFR2 & 753 & 17.4 & 118 & 15 & EFR2 & 5747 & 23.7 & 647 & 28 \\
\hline & DFR3 & 827 & 15.9 & 115 & 16 & EFR3 & 6569 & 31.5 & 472 & 57 \\
\hline & Avg. $( \pm S D)$ & $786( \pm 31)$ & $16.5( \pm 0.6)$ & $112( \pm 7)$ & $15( \pm 1)$ & Avg. $( \pm S D)$ & $6068( \pm 424)$ & $29.4( \pm 4.1)$ & $517( \pm 93)$ & $41( \pm 12)$ \\
\hline \multirow[t]{4}{*}{$45 S W+$ freeze-thaw } & DFS1 & 716 & 16.9 & 132 & 13 & EFS1 & 4282 & 31.6 & 251 & 34 \\
\hline & DFS2 & 723 & 20.5 & 107 & 10 & EFS2 & 4930 & 27 & 271 & 40 \\
\hline & DFS3 & 700 & 17.3 & 118 & 10 & EFS3 & 4600 & 24.8 & 307 & 40 \\
\hline & Avg. $( \pm S D)$ & $713( \pm 15)$ & $18.2( \pm 1.6)$ & $119( \pm 10)$ & $11( \pm 1)$ & Avg. $( \pm S D)$ & $4604( \pm 264)$ & $27.8( \pm 2.8)$ & $276( \pm 23)$ & $38( \pm 3)$ \\
\hline
\end{tabular}




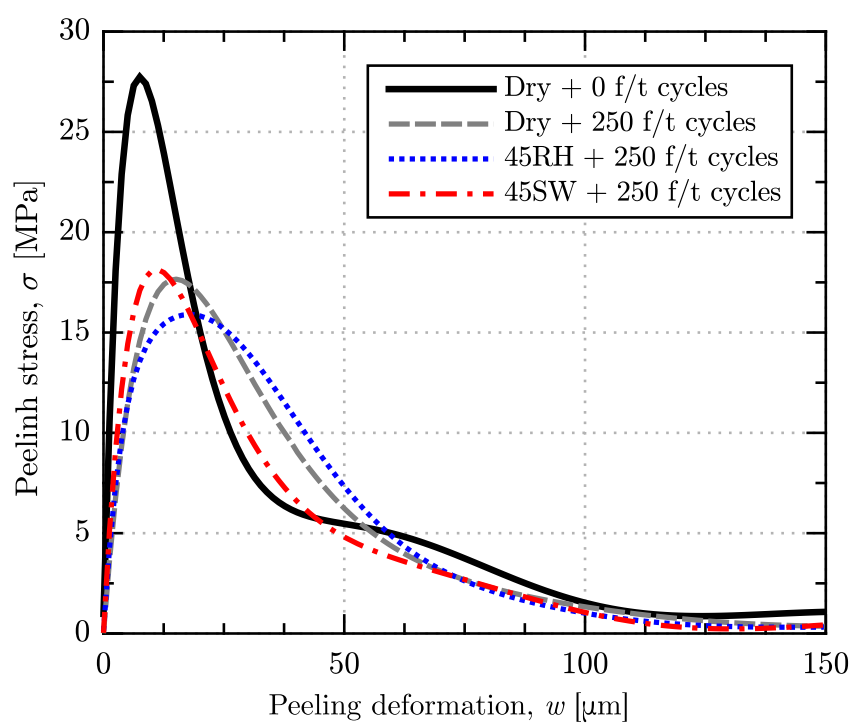

(a)

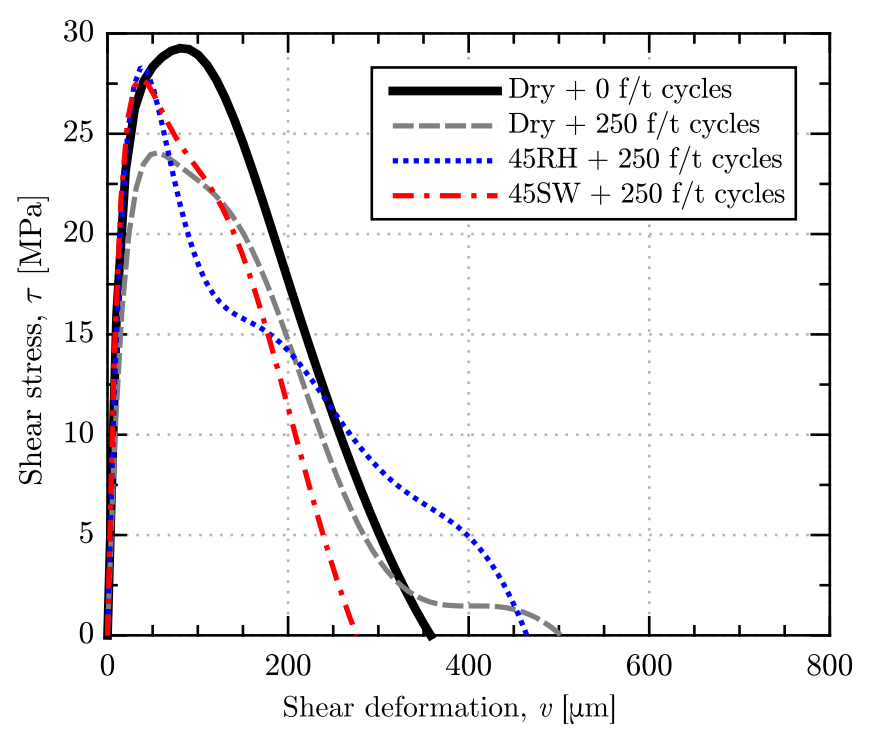

(b)

Fig. 17. Comparison of the obtained cohesive laws after additional freeze-thaw cycles: (a) Mode I, (b) Mode II.

\subsection{Comparative analysis of the results}

The design of adhesively bonded joints using the CZM is highly dependent on the critical fracture energy, maximum traction (peak stress) and critical deformation obtained from cohesive laws. Critical fracture energy, as the most influential factor, directly affects the strength of joints, see, for example, $[15,68]$. Maximum traction and critical deformation, on the other hand, influence the length of the damage process zone which is an important parameter for joints with short bondlines. In this section, the variation of these parameters for adhesives subjected to the isolated action of moisture or freeze-thaw cycles as well as their synergy are discussed. Fig. 18 demonstrates the effect of these ageing condition on the aforementioned parameters. The curves are normalised with respect to the average value obtained for control specimens.

It is apparent form Fig. 18 that both Mode I and Mode II critical fracture energies did not significantly change by the exposure to the high relative humidity condition, i.e. 45RH. A similar observation can be made for Mode II specimens aged in distilled water, while the same condition led to an average drop of $20 \%$ for Mode I critical fracture energy. In this respect, the harshest environment was immersion in saltwater which led to significant reductions of $29 \%$ and $11 \%$ on average for Mode I and Mode II critical fracture energies, respectively. This ageing condition also resulted in the most adverse effects on Mode II critical fracture energy when combined with freeze-thaw cycles. Interestingly, in the absence of moisture, freeze-thaw cycles are found to degrade the critical fracture energy by $11 \%$ and $19 \%$ for Mode I and Mode II, respectively. In summary, the critical fracture energy seems to be strongly affected by the type of the diffusing medium, i.e. vapour, distilled water or saltwater. In this regard, saltwater was found to be the most damaging condition for the cohesive laws of the studied adhesive. To prevent the prevailing effects of the diffusing medium, Liljedahl et al. [42] employed ageing scenarios in $80 \% \mathrm{RH}$ and $96 \% \mathrm{RH}$ conditions. Although the authors reported a direct correlation between the critical fracture energy, such data need to be interpreted with extreme caution and shall not be applied to immersion conditions.

The peak stresses were generally found to reduce in the presence of moisture. Similar to the case of critical fracture energy, these reductions were the highest for immersion in saltwater, with ca. $40 \%$ reduction, on average, irrespective of the loading mode. In comparison with Mode II, freeze-thaw cycles affected the Mode I peak stresses more adversely. Another noteworthy observation from Fig. 18 is the relatively negligible variations of the critical peeling deformation compared with the significant rise of the critical shear deformation with increasing moisture content. In particular, the critical shear deformation is found to increase by $79 \%$, in average, after immersion in distilled water. It should be also noted that, while the additional freeze-thaw cycling did not affect the critical shear deformation of dry or aged specimens in 45RH condition, it adversely affected the specimens initially aged in saltwater.

The more damaging effects of freeze-thaw when combined with saltwater or de-icing salts has been also outlined by Shao and Kouadio [69] and is believed to be a consequence of potential formation and expansion of the salt crystals. This subject, however, has not been fundamentally studied and more research is needed to address the underlying damaging mechanisms. In addition, further research is needed to shed light on the observed interfacial debonding failure of the specimens subjected to the freeze-thaw cycles after initially aged in distilled water at $45^{\circ} \mathrm{C}$. Last but not least, as the industrial application of adhesive joints often involves mixed-mode loading conditions, more experiments are needed to address the effect of environmental conditioning on mixed-mode behaviour.

\section{Concluding remarks}

The dependency of cohesive laws of an epoxy adhesive on moisture, freeze-thaw cycles and their synergy is obtained experimentally using a direct approach. Open-face DCB and ENF specimens are successfully used for this purpose. The obtained cohesive laws of the primary adhesive are shown to be unaffected by the used open-face specimen geometry, provided that a strong and considerably thin secondary adhesive bond is assured. In addition, the accuracy of the obtained cohesive laws were controlled by means of simulations of the experiments using the CZM approach. The FE analysis results were found to be in good agreement with the experiments, hence verifying the experimentally measured cohesive laws. The open-face specimens were exposed to $95 \% \mathrm{RH}$, immersion in distilled water and saltwater for three months to reach moisture saturation. Cohesive failure mode was observed for all the dry specimens and for those directly tested after exposure to wet conditions. Cohesive failure was also the dominant failure mode for specimens subjected to additional freeze-thaw cycles. The only exception was the interfacial debonding failure of specimens initially aged in distilled water at $45{ }^{\circ} \mathrm{C}$. This observation is believed to be mainly due to the presence of high amounts of moisture content at the interface. However, further research is needed to investigate the timedependency of interfacial strength in the presence of moisture. 


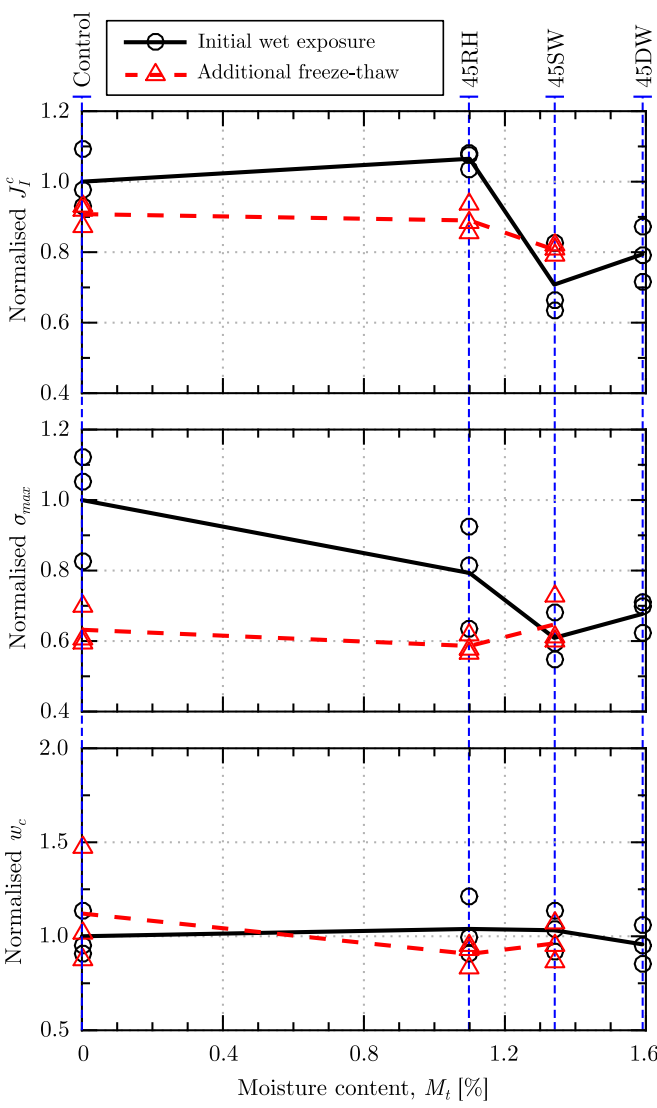

(a)

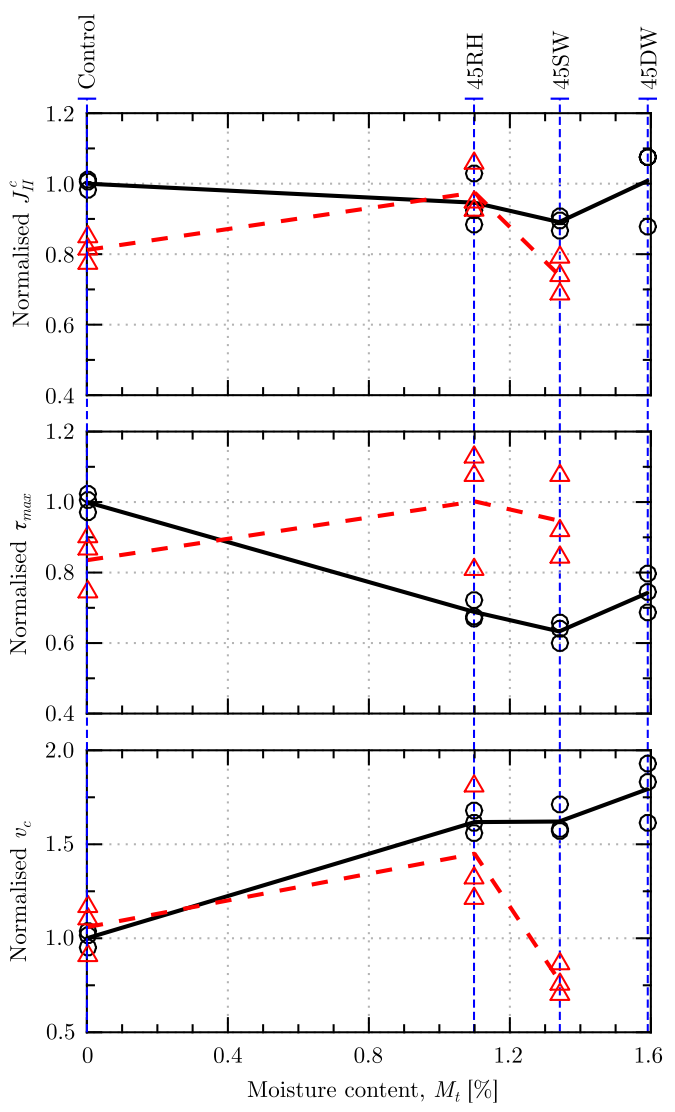

(b)

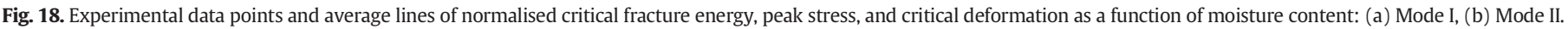

Exposure to the aforementioned ageing conditions were found to influence Mode I and Mode II cohesive laws of the studied epoxy adhesive differently. Fig. 19 shows schematic representation of these effects using simplified triangular cohesive laws. It can be seen that moisture mainly affected the Mode I cohesive law by reducing the peak stress. The reductions were found to be the largest for saltwater, and not directly proportional to the moisture content of the adhesive layer. The additional freeze-thaw cycles affected the Mode I cohesive law in a similar manner and irrespective of the initial ageing condition. However, the reductions did not exceed those initially caused by saltwater. For Mode II loading, in addition to the peak stress, moisture affected the critical deformation.
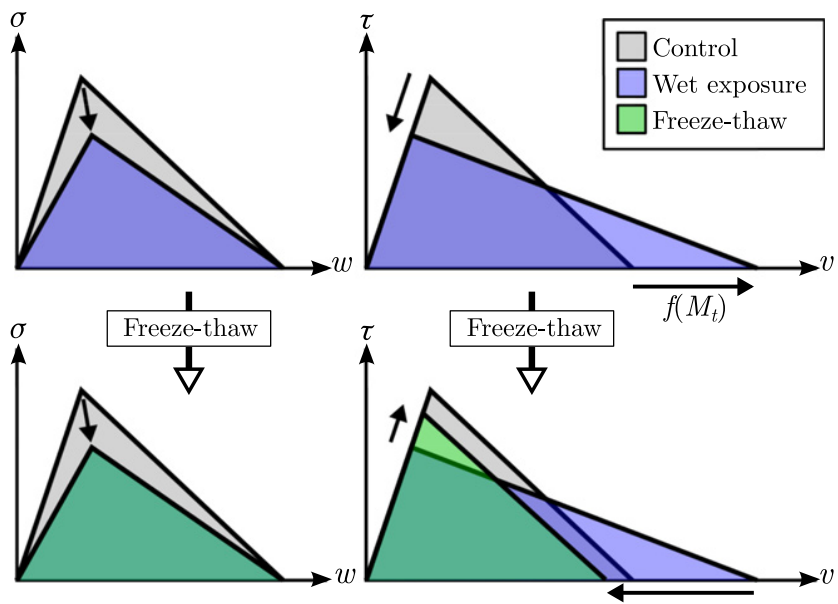

Fig. 19. Schematic representation of environmental effects on the simplified cohesive laws of the studied adhesive $\left(f\left(M_{t}\right)\right.$ is an arbitrary function of the moisture content).
In this regard, larger critical deformations were observed with increased moisture content. Hence, the critical fracture energy (area under cohesive law) was less severely affected as compared with that of Mode I. The freeze-thaw cycles generally caused reduction of Mode II critical fracture energy by adversely influencing the shear deformation and peak stress. The specimens initially immersed in saltwater were damaged the most, whereas those conditioned in 45RH did not experience any degradation.

The comparison of degradations of the peak stress of cohesive laws with tensile strength of adhesive dog-bone specimens exposed to the same wet conditions [49] revealed the improperness of the latter method when used to obtain traction parameter of cohesive laws. In addition, given the different response of Mode I and Mode II cohesive laws to environmental ageing conditions, the results are not extendable from one to the other, or interchangeable. Lastly, as the isolated and combined effects of the studied ageing conditions were captured by the cohesive laws, they can be used as input for the prediction of durability and long-term performance of adhesively bonded joints.

\section{Acknowledgements}

The authors would like to acknowledge the Swedish Research Institute (FORMAS) (Grant 2011-415) for its financial support.

\section{References}

[1] M.A. Saeimi Sadigh, G. Marami, Investigating the effects of reduced graphene oxide additive on the tensile strength of adhesively bonded joints at different extension rates, Mater. Des. 92 (2016) 36-43, http://dx.doi.org/10.1016/j.matdes.2015. 12.006.

[2] S. Murakami, Y. Sekiguchi, C. Sato, E. Yokoi, T. Furusawa, Strength of cylindrical butt joints bonded with epoxy adhesives under combined static or high-rate 
loading, Int. J. Adhes. Adhes. 67 (2016) 86-93, http://dx.doi.org/10.1016/j.ijadhadh. 2015.12.030.

[3] X. Zhan, C. Gu, H. Wu, H. Liu, J. Chen, J. Chen, et al., Experimental and numerical analysis on the strength of $2060 \mathrm{Al}-\mathrm{Li}$ alloy adhesively bonded T joints, Int. J. Adhes. Adhes. 65 (2016) 79-87, http://dx.doi.org/10.1016/j.jiadhadh.2015.11.010.

[4] H. Zhou, H.Y. Liu, H. Zhou, Y. Zhang, X. Gao, Y.W. Mai, On adhesive properties of nano-silica/epoxy bonded single-lap joints, Mater. Des. 95 (2016) 212-218, http:// dx.doi.org/10.1016/j.matdes.2016.01.055.

[5] X. Jiang, H. Kolstein, F.S.K. Bijlaard, Moisture diffusion and hygrothermal aging in pultruded fibre reinforced polymer composites of bridge decks, Mater. Des. 37 (2012) 304-312, http://dx.doi.org/10.1016/j.matdes.2012.01.017.

[6] Y. Zhou, K. Jiang, M. Gou, N. Li, P. Zhu, D. Wang, et al., Prediction of debonding strength of tensile hybrid bonded joints using fracture mechanics, Mater. Des. 61 (2014) 87-100, http://dx.doi.org/10.1016/j.matdes.2014.04.068.

[7] S.S. Wang, J.F. Mandell, F.J. McGarry, An analysis of the crack tip stress field in DCB adhesive fracture specimens, Int. J. Fract. 14 (1978) 39-58, http://dx.doi.org/10. 1007/BF00032383.

[8] M. Charalambides, A.J. Kinloch, Y. Wang, J.G. Williams, On the analysis of mixed-mode failure, Int. J. Fract. 54 (1992) 269-291, http://dx.doi.org/10.1007/BF00035361.

[9] T. Andersson, A. Biel, On the effective constitutive properties of a thin adhesive layer loaded in peel, Int. J. Fract. 141 (2006) 227-246, http://dx.doi.org/10.1007/s10704006-0075-6.

[10] T. Walander, A. Biel, U. Stigh, Temperature dependence of cohesive laws for an epoxy adhesive in Mode I and Mode II loading, Int. J. Fract. 183 (2013) 203-221, http://dx.doi.org/10.1007/s10704-013-9887-3.

[11] K. Leffler, K.S. Alfredsson, U. Stigh, Shear behaviour of adhesive layers, Int. J. Solids Struct. 44 (2007) 530-545, http://dx.doi.org/10.1016/j.ijsolstr.2006.04.036.

[12] G. Barenblatt, Equilibrium cracks formed during brittle fracture rectilinear cracks in plane plates, J. Appl. Math. Mech. (1959).

[13] Z. Suo, G. Bao, B. Fan, Delamination R-curve phenomena due to damage, J. Mech. Phys. Solids 40 (1992) 1-16, http://dx.doi.org/10.1016/0022-5096(92)90198-B.

[14] J.C.S. Azevedo, R.D.S.G. Campilho, F.J.G. da Silva, T.M.S. Faneco, R.M. Lopes, Cohesive law estimation of adhesive joints in mode II condition, Theor. Appl. Fract. Mech. 80 (2015) 143-154, http://dx.doi.org/10.1016/j.tafmec.2015.09.007.

[15] S. Sugiman, A.D. Crocombe, I.A. Aschroft, Modelling the static response of unaged adhesively bonded structures, Eng. Fract. Mech. 98 (2013) 296-314, http://dx.doi. org/10.1016/j.engfracmech.2012.10.014

[16] U. Stigh, K.S. Alfredsson, T. Andersson, A. Biel, T. Carlberger, K. Salomonsson, Some aspects of cohesive models and modelling with special application to strength of adhesive layers, Int. J. Fract. 165 (2010) 149-162, http://dx.doi.org/10.1007/s10704010-9458-9.

[17] U. Stigh, K.S.A. And, A. Biel, Measurement of cohesive laws and related problems, Proceeding ASME Int. Mech. Eng. Congr. Expo. (2009) 293-298, http://dx.doi.org/ 10.1115/IMECE2009-10474.

[18] U. Stigh, Damage and crack growth analysis of the double cantilever beam specimen, Int. J. Fract. 37 (1988) R13-R18.

[19] G. Ji, Z. Ouyang, G. Li, S. Ibekwe, S.S. Pang, Effects of adhesive thickness on global and local mode-I interfacial fracture of bonded joints, Int. J. Solids Struct. 47 (2010) 2445-2458, http://dx.doi.org/10.1016/j.ijsolstr.2010.05.006.

[20] U.T.F. Carvalho, R.D.S.G. Campilho, Application of the direct method for cohesive law estimation applied to the strength prediction of double-lap joints, Theor. Appl. Fract. Mech. 85 (2016) 140-148, http://dx.doi.org/10.1016/j.tafmec.2016.08.018.

[21] M. Heshmati, R. Haghani, M. Al-Emrani, Environmental durability of adhesively bonded FRP/steel joints in civil engineering applications: state of the art, Compos. Part B 81 (2015) 259-275, http://dx.doi.org/10.1016/j.compositesb.2015.07.014.

[22] M. Gholami, A.R.M. Sam, J.M. Yatim, M.M. Tahir, A review on steel/CFRP strengthening systems focusing environmental performance, Constr. Build. Mater. 47 (2013) 301-310, http://dx.doi.org/10.1016/j.conbuildmat.2013.04.049.

[23] X.-L. Zhao, Y. Bai, R. Al-Mahaidi, S. Rizkalla, Effect of dynamic loading and environmental conditions on the bond between CFRP and steel: state-of-the-art review, J. Compos. Constr. 18 (2014), A4013005. http://dx.doi.org/10.1061/(ASCE)CC.19435614.0000419.

[24] R.A. Pethrick, Design and ageing of adhesives for structural adhesive bonding - a review, Proc. Inst. Mech. Eng. LJ. Mater. Des. Appl. 229 (2015) 349-379, http://dx.doi. org/10.1177/1464420714522981

[25] S.A. Grammatikos, M. Evernden, J. Mitchels, B. Zafari, J.T. Mottram, G.C. Papanicolaou, On the response to hygrothermal aging of pultruded FRPs used in the civil engineering sector, Mater. Des. 96 (2016) 283-295, http://dx.doi.org/10. 1016/j.matdes.2016.02.026.

[26] J.W. Chin, T. Nguyen, K. Aouadl, Effects of environmental exposure on fiberreinforced plastic (FRP) materials used in construction, J. Compos. Technol. Res. 19 (1997) 205-213.

[27] V.M. Karbhari, Durability of Composites for Civil Structural Applications, Woodhead Pub., 2007

[28] P. Böer, L. Holliday, T.H.-K. Kang, Independent environmental effects on durability of fiber-reinforced polymer wraps in civil applications: a review, Constr. Build. Mater. 48 (2013) 360-370, http://dx.doi.org/10.1016/j.conbuildmat.2013.06.077.

[29] X. Jiang, J. Song, X. Qiang, H. Kolstein, F. Bijlaard, Moisture absorption/desorption effects on flexural property of glass-fiber-reinforced polyester laminates: three-point bending test and coupled hygro-mechanical finite element analysis, Polymers (Basel, Switz.) 8 (2016) 290, http://dx.doi.org/10.3390/polym8080290.

[30] A. Agarwal, S.J. Foster, E. Hamed, T.S. Ng, Influence of freeze-thaw cycling on the bond strength of steel-FRP lap joints, Compos. Part B 60 (2014) 178-185, http:// dx.doi.org/10.1016/j.compositesb.2013.12.024.

[31] P.K. Dutta, Structural fiber composite materials for cold regions, J. Cold Reg. Eng. 2 (1988) 124-134, http://dx.doi.org/10.1061/(ASCE)0887-381X(1988)2:3(124).
[32] M. Di Ludovico, F. Piscitelli, A. Prota, M. Lavorgna, G. Mensitieri, G. Manfredi, Improved mechanical properties of CFRP laminates at elevated temperatures and freeze-thaw cycling, Constr. Build. Mater. 31 (2012) 273-283, http://dx.doi.org/ 10.1016/j.conbuildmat.2011.12.105.

[33] A. Agarwal, S. Foster, E. Hamed, Z. Vrcelj, Testing of steel-CFRP adhesive joints under freeze-thaw cycling, Mater. to Struct. Adv. Through Innov. - Proc. 22nd Australas. Conf. Mech. Struct. Mater ACMSM 2013 (2012) 801-806.

[34] V. Toufigh, V. Toufigh, H. Saadatmanesh, Behavior of FRP bonded to steel under freeze thaw cycles, Steel Compos. Struct. 14 (2013) 41-55, http://dx.doi.org/10. 12989/scs.2013.14.1.041.

[35] A. Agarwal, S.J. Foster, E. Hamed, Wet thermo-mechanical behavior of steel-CFRP joints - an experimental study, Compos. Part B 83 (2015) 284-296, http://dx.doi. org/10.1016/j.compositesb.2015.08.025.

[36] Ankit Agarwal, Ehab Hamed, S.J. Foster, Effect of adhesive thickness on the interfacial stresses in steel-FRP lap-joints under freeze-thaw cycling, APFIS 2013 Conf. Proc. (2013) 11-13.

[37] A. Agarwal, S.J. Foster, E. Hamed, Testing of new adhesive and CFRP laminate for steel-CFRP joints under sustained loading and temperature cycles, Compos. Part B 99 (2016) 235-247, http://dx.doi.org/10.1016/j.compositesb.2016.06.039.

[38] M.H. Kabir, S. Fawzia, T.H.T. Chan, Durability of CFRP strengthened circular hollow steel members under cold weather: experimental and numerical investigation, Constr. Build. Mater. 123 (2016) 372-383, http://dx.doi.org/10.1016/j.conbuildmat.2016.06.116.

[39] M.H. Kabir, S. Fawzia, T.H.T. Chan, J.C.P.H. Gamage, Comparative durability study of CFRP strengthened tubular steel members under cold weather, Mater. Struct. (2015) http://dx.doi.org/10.1617/s11527-015-0610-x.

[40] J.W. Wylde, J.K. Spelt, Measurement of adhesive joint fracture properties as a function of environmental degradation, Int. J. Adhes. Adhes. 18 (1998) 237-246, http:// dx.doi.org/10.1016/S0143-7496(98)00028-1.

[41] W. Loh, A. Crocombe, M. Abdel Wahab, I. Ashcroft, Environmental degradation of the interfacial fracture energy in an adhesively bonded joint, Eng. Fract. Mech. 69 (2002) 2113-2128, http://dx.doi.org/10.1016/S0013-7944(02)00004-8.

[42] C.D.M. Liljedahl, A.D. Crocombe, M.A. Wahab, I.A. Ashcroft, Modelling the environmental degradation of adhesively bonded aluminium and composite joints using a CZM approach, Int. J. Adhes. Adhes. 27 (2007) 505-518, http://dx.doi.org/10.1016/ j.ijadhadh.2006.09.015.

[43] A. Ameli, M. Papini, J.K. Spelt, Hygrothermal degradation of two rubber-toughened epoxy adhesives: application of open-faced fracture tests, Int. J. Adhes. Adhes. 31 (2011) 9-19, http://dx.doi.org/10.1016/j.jjadhadh.2010.10.001.

[44] J.R. Rice, A path independent integral and the approximate analysis of strain concentration by notches and cracks, J. Appl. Mech. 35 (1968) 379, http://dx.doi.org/10. $1115 / 1.3601206$

[45] ASTM, Standard E8/E8M-13a. "Standard Test Methods for Tension Testing of Metallic Materials", 2013, http://dx.doi.org/10.1520/E0008_E0008M-13A.

[46] M. Heshmati, Hygrothermal Durability of Adhesively Bonded FRP/Steel Joints, Chalmers University of Technology, Gothenburg, Sweden, 2015

[47] M. Heshmati, R. Haghani, M. Al-Emrani, Durability of FRP/steel double-lap shear joints: effects of moisture, de-icing salts, temperature, and FRP type, Compos. Part B (2016).

[48] J.M.C. Cadei, T.J. Stratford, L.C. Hollaway, W.G. Duckett, Strengthening Metallic Structures Using Externally Bonded Fibre - Reinforced Polymers, 44, 2004 174-180.

[49] M. Heshmati, R. Haghani, M. Al-Emrani, Effects of moisture on the long-term performance of adhesively bonded FRP/steel joints used in bridges, Compos. Part B 92 (2016) 1-16, http://dx.doi.org/10.1016/j.compositesb.2016.02.021.

[50] J.L. Högberg, B.F. Sørensen, U. Stigh, Constitutive behaviour of mixed mode loaded adhesive layer, Int. J. Solids Struct. 44 (2007) 8335-8354, http://dx.doi.org/10 1016/j.jijsolstr.2007.06.014.

[51] B.F. Sørensen, P. Kirkegaard, Determination of mixed mode cohesive laws, Eng Fract. Mech. 73 (2006) 2642-2661, http://dx.doi.org/10.1016/j.engfracmech.2006. 04.006 .

[52] A. Biel, U. Stigh, Effects of constitutive parameters on the accuracy of measured fracture energy using the DCB-specimen, Eng. Fract. Mech. 75 (2008) 2968-2983, http://dx.doi.org/10.1016/j.engfracmech.2008.01.002.

[53] ASTM, Standard D3433-99. "Standard Test Method for Fracture Strength in Cleavage of Adhesives in Bonded Metal Joints", 2012, http://dx.doi.org/10.1520/D3433-99R12.2.

[54] P. Olsson, U. Stigh, On the determination of the constitutive properties of thin interphase layers - an exact inverse solution, Int. J. Fract. 41 (1989) 71-76, http://dx.doi. org/10.1007/BF00018870.

[55] F. Nilsson, Large displacement aspects on fracture testing with double cantilever beam specimens, Int. J. Fract. 139 (2006) 305-311, http://dx.doi.org/10.1007/ s10704-006-8376-3.

[56] A.J. Russell, K.N. Street, Factors affecting the interlaminar fracture energy of graphite/epoxy laminates, Prog. Sci. Eng. Compos. 279-86 (1982).

[57] H. Chai, Shear fracture, Int. J. Fract. 37 (1988) 137-159, http://dx.doi.org/10.1007/ BF00041716.

[58] S. Goutianos, R. Arévalo, B.F. Sørensen, T. Peijs, Effect of processing conditions on fracture resistance and cohesive laws of binderfree all-cellulose composites, Appl. Compos. Mater. 21 (2014) 805-825, http://dx.doi.org/10.1007/s10443-013-9381-0.

[59] T. Walander, System for Measurement of Cohesive Laws, University of Skövde, 2009,

[60] S. Goutianos, B.F. Sørensen, The application of J integral to measure cohesive laws under large-scale yielding, Eng. Fract. Mech. 155 (2016) 145-165, http://dx.doi. org/10.1016/j.engfracmech.2016.01.004.

[61] S. Marzi, A. Biel, U. Stigh, On experimental methods to investigate the effect of layer thickness on the fracture behavior of adhesively bonded joints, Int. J. Adhes. Adhes. 31 (2011) 840-850, http://dx.doi.org/10.1016/j.ijadhadh.2011.08.004.

[62] M. Heshmati, R. Haghani, M. Al-Emrani, Durability of bonded FRP-to-steel joints: effects of moisture, de-icing salt solution, temperature and FRP type, Accept Publ. Compos Part B Eng. (2016). 
[63] A.B. de Morais, Analysis of the metal adhesively bonded double cantilever beam specimen, Int. J. Adhes. Adhes. 61 (2015) 8-14, http://dx.doi.org/10.1016/j. ijadhadh.2015.04.010.

[64] D.W. Spring, G.H. Paulino, A growing library of three-dimensional cohesive elements for use in ABAQUS, Eng. Fract. Mech. 126 (2014) 190-216, http://dx.doi. org/10.1016/j.engfracmech.2014.04.004.

[65] U. Stigh, A. Biel, Shear properties of an adhesive layer exposed to a compressive load, Prog. Mater. Sci. 3 (2014) 1626-1631, http://dx.doi.org/10.1016/j.mspro.2014.06. 262.

[66] B.F. Sørensen, S. Goutianos, Mixed mode cohesive law with interface dilatation, Mech. Mater. 70 (2014) 76-93, http://dx.doi.org/10.1016/j.mechmat.2013.11.006.
[67] S. Li, M. Thouless, A. Waas, J. Schroeder, P. Zavattieri, Use of a cohesive-zone model to analyze the fracture of a fiber-reinforced polymer? Matrix composite, Compos. Sci. Technol. 65 (2005) 537-549, http://dx.doi.org/10.1016/j.compscitech.2004.08. 004.

[68] N.D. Fernando, Bond Behaviour and Debonding Failures in CFRP-Strengthened Steel Members, The Hong Kong Polytechnic University, 2010.

[69] Y. Shao, S. Kouadio, Durability of fiberglass composite sheet piles in water, J. Compos. Constr. 6 (2002) 280-287, http://dx.doi.org/10.1061/(ASCE)10900268(2002)6:4(280). 